\title{
LA DICOTOMÍA PÚBLICO / PRIVADO: ESTADO DE LA CUESTIÓN Y SU FUNCIÓN EN DERECHO ADMINISTRATIVO
}

\author{
THE PUBLIC / PRIVATE DICHOTOMY: STATE OF THE \\ QUESTION AND ITS FUNCTION IN ADMINISTRATIVE LAW
}

ALEJANDRO VERGARA BLANCO*

\section{RESUMEN}

En este escrito el autor realiza una detallada exposición de la actual consagración y discusión de la dicotomía público / privado en Chile. Antecedido de una revisión del tema en la historia jurídica y en el derecho comparado, se expone el estado de la cuestión ante la actual normativa constitucional y legal chilena; revisa su acogimiento en la jurisprudencia a través de una casuística relevante; y, expone la discusión que se ha producido en la doctrina nacional. En fin, el autor analiza y se pronuncia sobre la estructura, identidad y función de la dicotomía, desde la perspectiva del derecho administrativo.

Palabras clave: Supletoriedad normativa, Dicotomía público / privado, Derecho Público, Derecho Privado, Derecho administrativo, Derecho civil.

*Profesor Titular de Derecho Administrativo, Pontificia Universidad Católica de Chile, Santiago, Chile. Doctor en Derecho, Universidad de Navarra. Post Doctorado en Derecho Université de Pau et des Pays de l'Adour. Correo: alvergar@uc.cl. ORCID: https://orcid.org/0000-0003-0111-7641.

Artículo recibido el 20 de octubre de 2021 y aceptado para su publicación el 15 de diciembre de 2021 . 


\section{ABSTRACT}

In this writing the author makes a detailed exposition of the current consecration and discussion of the public/private dichotomy in Chile. Preceded by a review of the subject in legal history and comparative law, the state of the matter is exposed before the current constitutional and legal regulations; then it reviews its reception in jurisprudence through a relevant casuistry; and, finally, it reviews the discussion that has taken place in the national doctrine. Finally, the author analyzes and pronounces on the structure, identity and function of the dichotomy, from the perspective of administrative law.

Keywords: Supplementary laws, Public / private dichotomy, Public Law, Private Law, Administrative Law, Civil Law.

\section{INTRODUCCIÓN: HUELLA HISTÓRICA E IMPERATIVO ACTUAL DE LA DICOTOMÍA}

1.- En derecho propiamente chileno, los conceptos derecho público y derecho privado, tanto separadamente como conformando la dicotomía, han estado presentes desde el principio de la República. La Constitución Política de la República (CPR) (desde la de 1833 hasta la de 1980), el Código Civil (de 1857) y muchas leyes posteriores han poblado sus textos con nociones relativas a lo público y lo privado, consignando las expresiones de la paridad o sus sinónimos. Sin embargo, no hay definiciones constitucionales o legales que permitan demarcar el contorno de esos polos: sus límites. Así, esta distinción se ha seguido utilizando en la literatura jurídica hasta hoy sin mucha conciencia de sus efectos sistémicos o globales.

Fue de la mano de Andrés Bello que por vez primera se incorpora la expresión «derecho público» en la legislación chilena, esto es, una de las partes de la dicotomía, en los arts.547 inc. $2^{\circ}$ y 1462 del Código Civil. Décadas después, en los años 1991 y 2003 se dio un paso más significativo, pues el legislador ya no solo se refirió a una de las partes de la dicotomía, sino que consagra la partitio íntegra. Ello ocurre en dos leyes especiales de derecho administrativo, que constituyen así casos paradigmáticos:

i) Por una parte, el artículo 21 incs. $1^{\circ}$ y $2^{\circ}$ del Decreto con Fuerza de 
Ley $N^{\circ} 164$, de 1991 [cuyo texto fue fijado por el Decreto Supremo $N^{\circ} 900$, de 1996], Ley de Concesiones de Obras Públicas, contrapone las "normas de derecho público" con las "normas de derecho privado". Su texto es el siguiente:

"El concesionario cumplirá las funciones incorporadas en el contrato de concesión con arreglo a las normas del derecho público, especialmente en lo referente a sus relaciones con el Ministerio, a las regulaciones sobre los regímenes de construcción y explotación de la obra y al cobro de las tarifas, su sistema de reajuste y las contraprestaciones con el Fisco, que conforman el régimen económico del contrato. Igualmente, deberá cumplir las normas que regulan la actividad dada en concesión”.

"En cambio, en lo que se refiere a sus derechos y obligaciones económicas con terceros la sociedad concesionaria se regirá por las normas del derecho privado y, en general, podrá realizar cualquier operación lícita, sin necesidad de autorización previa del Ministerio de Obras Públicas, con las solas excepciones que regula expresamente esta ley y las que se estipulen en el contrato". [el destacado es agregado]

ii) Por otra, el artículo $1^{\circ}$ de la Ley $N^{o} 19.886$, de 2003, de Bases sobre Contratos Administrativos de Suministro y Prestación de Servicios, realiza igual contraposición poniendo a las "normas de derecho público" de frente a las "normas del derecho privado". Señala la Ley:

“Los contratos (...) se ajustarán a las normas y principios del presente cuerpo legal y de su reglamentación. Supletoriamente, se les aplicarán las normas de Derecho Público y, en defecto de aquéllas, las normas del Derecho Privado". [sic, con mayúsculas en el original; el destacado es agregado] ${ }^{1}$

\footnotetext{
${ }^{1}$ Cabe destacar que existe en estas normas algo poco usual: una referencia a «Derecho» (esto es, al ius en contraposición de la lex). En la norma de 2003 existe un orden de prelación de fuentes supletorias: derecho público, primero; derecho privado, después; además, es raro que se anteponga la aplicación del reglamento a las demás leyes, en este caso el reglamento especial sobre contratación, el que tiene menor jerarquía normativa que una ley, lo que es problemático; en fin, si entendemos que es un mandato de
} 
Consagran así ambas normas una distinción o un orden de prelación de aplicación de normas, respectivamente; así, la mera referencia decimonónica a una parte de la partitio se transforma ahora en un clasificatorio del derecho todo.

2.- El problema actual, entonces, para abogados, jueces y juristas es que ambas normas los obliga a una tarea epistemológica/ontológica: clasificar las leyes en públicas o privadas. Cabe preguntarse al respecto si lo que se quiso significar en 1857 con la apelación al "derecho público" y su contrario implícito (el "derecho privado") o sus sinónimos es lo mismo que más contemporáneamente han querido decir esas leyes de 1991 y 2003. La norma de 1991, distingue dos regímenes jurídicos, uno de derecho público, otro de derecho privado; por su parte, la ley de 2003 establece una técnica de integración normativa, según la cual los vacíos normativos se deben rellenar aplicando correlativamente, como supletorias, primero normas de derecho público y luego normas de derecho privado. Para ambos casos es esencial postular un método para la identificación de cada norma y así asignarle identidad respectiva: ya de derecho público, ya de derecho privado; esto es, hacer operativa la dicotomía público / privado. De ahí que pareciera que el estudio de la dicotomía es hoy un imperativo en derecho chileno ${ }^{2}$; de ahí que se ofrece en este trabajo un análisis sobre el status quaestionis de la materia y algunos desarrollos sobre su utilidad actual, en especial, para el derecho administrativo, pues es la disciplina en que son más notorios los efectos de una eventual ausencia de teorías generales sobre la dicotomía, como muestro en este trabajo.

Para constatar esa hipótesis cabe analizar primero la dicotomía público / privado en las fuentes, esto es, en la legislación, jurisprudencia y doctrina. Al respecto, cabe recordar que ni el legislador ni el juez, en sus respectivas labores, tienen el designio epistemológico de identificar los

integración puramente normativo ¿elimina la posibilidad de recurrir a principios jurídicos para el relleno de lagunas? Salvo que entendamos que la referencia legislativa a normas de derecho público y derecho privado es también a principios jurídicos, lo que sin embargo no es el tenor expreso: la ley se refiere a "normas".

${ }^{2}$ Imperativo que, cabe reconocer, entre nosotros ya fue observado antes por Vergara Blanco, Alejandro, "Dicotomía público y privado en derecho administrativo, supletoriedad y clasificación de normas en públicas y privadas", en Vergara, A.; Bocksang, G. (coords.), Público y privado en derecho administrativo. Actas VIII Jornadas de Derecho Administrativo, Thomson Reuters, Santiago, 2011, pp. 305-326; y Vergara Blanco, Alejandro, "La 'summa divisio iuris' público-privado y la integración normativa en materias administrativas", Revista de Derecho Privado, 2014, N²6, pp. 43-69. 
campos de las disciplinas o partes del derecho. Esa es una labor de la doctrina o dogmática jurídica (como ciencia). Pero el legislador y los jueces pueden respectivamente ayudar a través de sus decisiones a identificar los campos de lo privado (= civil) y de lo público (= administrativo); o mediante normas o sentencias coherentes con la partitio. De ahí que observo la partitio en esas tres fuentes del derecho. No agrego al análisis de las fuentes el caso de los principios generales del derecho, pues ellos son un sustituto de las leyes, y seguirán la suerte de las disciplinas en que operan. Igualmente, aún no se inserta en nuestra cultura la clasificación de los principios según la dicotomía.

3.- El amplio reconocimiento de la summa diviso público y privado en el derecho chileno origina, como objetivo, observar no solo el encadenamiento histórico que vincula al actual derecho con la más antigua tradición de la divisio, sino, además, cabe preguntarse por el significado actual de la partitio desde la perspectiva del derecho administrativo y las consecuencias para dos aspectos esenciales de esa (y toda) disciplina: su autonomía; y la definición de su campo propio. Así:

i) En cuanto a la autonomía, a pesar de que la normativa está plagada de menciones a lo público y privado, al derecho público y al derecho privado, y otros giros sinónimos a los anteriores, no ofrece un criterio de distinción, ni orgánico ni material, sobre qué es lo público y qué es lo privado o los contornos del derecho privado y del derecho público. Por su parte, como vemos infra, en general, la doctrina y la jurisprudencia se han referido casi a una única consecuencia de esta división: la supletoriedad del Código Civil y de otros códigos; esto es, la aplicación supletoria de esos códigos a casos de naturaleza administrativa, y habitualmente ha quedado de lado la perspectiva epistemológica de definición del campo objetivo de la partitio, lo que es relevante para identificar eventuales deslizamientos territoriales, metáfora que utilizo para graficar los fenómenos de aplicación de normas de alguna rama del derecho privado (= derecho civil) en ramas de derecho público (= derecho administrativo), que es lo más habitual, no así viceversa; $\mathrm{y}$,

ii) En cuanto al contorno del actual derecho administrativo, cabe antes que nada identificar y clasificar uno a uno los usos del derecho privado en la disciplina: su influencia y su utilización actual a través de los fenómenos de préstamo, transposición, importación, trasplante, injerto o como se le quiera llamar, los que ocurren en la práctica, y que son inevitables dado 
lo lagunoso del corpus normativo especial del derecho administrativo. En seguida, cabe revisar los efectos de tales préstamos en la autonomía del derecho administrativo, y aquilatar si son mera fuente formal y no material; esto es, facultativa, contingente o transitoria, y no permanente.

De lo anterior fluye, entonces, la relevancia actual para el Derecho Administrativo del estudio de la partición público/privado quizás más que para toda otra disciplina (como queda en evidencia al revisar la bibliografía chilena y de derecho comparado: véase infra).

4.- La supletoriedad es un método de integración normativa que opera integrando de un modo subsidiario el texto de las leyes de carácter general o común respecto de aquellas de carácter singular o de excepción (llamadas en la práctica, igualmente, leyes "especiales"). Esta técnica es utilizada en aquellos casos en que así lo disponga expresa e inequívocamente el legislador, o en aquellos casos en que la interpretación ofrecida por el jurista o por el juez ha resultado insuficiente para cubrir una laguna legal en el ordenamiento singular; en tales situaciones es necesario recurrir al ordenamiento legal general o común para extraer de él la norma que pueda cubrir el vacío. La CPR no ofrece una respuesta concreta a la supletoriedad del Código Civil (= derecho privado) respecto del derecho administrativo (= derecho público), lo cual ha contribuido a que en Chile se hayan generado discusiones doctrinarias relativas a una supuesta supletoriedad general de ese código para casos de naturaleza pública (=derecho administrativo), fundándose en el art. 4 CC. Como reviso infra en doctrina y jurisprudencia, el tema de la aplicación supletoria del CC domina la discusión; de ahí su conexión técnica con la dicotomía.

5.- La distinción entre derecho público y derecho privado es relevante hoy en Chile para la adjudicación del derecho. De ahí que en la praxis es crucial para jueces y justiciables tener una clara noción de la dicotomía y precisión de sus contornos: tanto del derecho público (usualmente, el derecho administrativo) como del derecho privado (usualmente, del derecho civil, llamado también derecho común), pues ellos deben ubicar o encontrar las normas aplicables a cada caso; ante lo cual la búsqueda de la autonomía de una disciplina no debe ser confundida con el intento por lograr una especie de trofeo para "privatistas" o "publicistas", cada vez que "logran" o "impiden" la aplicación de normas de una disciplina en otra diversa; el tema está conectado con la necesidad de que las parcelas disciplinarias sean objeto de respuestas doctrinarias o resoluciones jurisprudenciales 
coherentes con la ubicación en uno u otro polo del derecho; desde ahí que este intento de racionalidad tenga por vocación ser un aporte práctico a la mejor adjudicación del derecho.

En este trabajo observo primero la dicotomía público / privado en la historia jurídica y el derecho comparado (II). Luego, reviso el estado de la cuestión ante cada una de las fuentes, esto es, normativa (III), jurisprudencia (IV) y doctrina (V). Con este panorama podré formular algunas ideas sobre la actual estructura, identidad y función de la dicotomía en derecho chileno (VI).

\section{LA DIVISIÓN PÚBLICO/PRIVADO EN LA HISTORIA JURÍDICA Y EN EL DERECHO COMPARADO}

Previo a la revisión de la dicotomía en las fuentes propiamente chilenas, cabe observarla más ampliamente en la historia jurídica (1) y en el derecho comparado (2), la que como veremos, tiene una estrecha vinculación con la conformación unitaria o dual de los tribunales de justicia (3).

\section{La dicotomía público / privado en la historia jurídica}

La partición público / privado ha sido observada desde distintas perspectivas, como la filosofía, la sociología, la historia y, por cierto, el derecho. ${ }^{3}$ En el derecho, la summa divisio público/privado surgió en Roma, ${ }^{4}$ en un fragmento doctrinario de las Instituciones de Ulpiano (redactado entre el 212 y el 213 d.C.) recogido luego en el Corpus Iuris Civilis justinianeo (entre el 530 y el 533 d.C.); el famoso texto es del siguiente tenor: ${ }^{5}$

\footnotetext{
${ }^{3}$ Véase las valiosas perspectivas filosóficas sobre la esfera pública y privada en: ARENDT, Hannah, The Human Condition, Paidós, Barcelona, 1993, capítulo II, pp. 37-95 y en HABERMAS, Jürgen, Historia y crítica de la opinión pública, G. Gili, Barcelona, 1982, pp. 94-123, quienes lo han desarrollado de modo polémico entre ellos. En una perspectiva de ética jurídica, véase: LIFANTE VIDAL, Isabel, Lo público y lo privado. Problemas de ética jurídica, Editorial Bdef, Buenos Aires, 2018.

${ }^{4}$ Sobre el origen e historia en Roma, véase: NoCERA, Guglielmo, Il binomio pubblico-privato nella storia del diritto, Edizioni Scientifiche Italiana, Nápoles, 1989, p. 7 y passim; y últimamente SorDI, Bernardo, Diritto pubblico e diritto Privato. Una genealogía storica, Il Mulino, Bolonia, 2020.

${ }^{5}$ Digesto, I, I, 1, 2 (= Institutas, I, 1, 4) (traducción según edición de García Del Corral, Idelfonso, Cuerpo del Derecho Civil Romano, Ed. Jaime Molinas, Barcelona, 1889).
} 
"Huius studii duae sunt positions, publicum et privatum. Publicum ius est, quod ad estatum rei Romanae spectat, privatum, quod ad singulorum utilitatem [pertinet]; sunt enim quaedam publice utilia, quaedam privatim".

[Traducción: "Dos son los aspectos de este estudio [del derecho], el público y el privado. Es derecho público, el que se refiere al estado de la cosa romana; privado, el que [pertenece] a la utilidad de cada individuo; pues unas cosas son útiles pública, y otras privadamente".]

En la Edad Media esta clasificación habría de desaparecer, dado que romanistas y canonistas eran férreos defensores del derecho común. ${ }^{6}$ Luego la dicotomía reaparece en la literatura jurídica de la época moderna, a mediados del siglo XVII, época en que se publicarían obras con el título de derecho privado o de derecho público. ${ }^{7}$ A partir de entonces y hasta hoy, esta divisio no ha desaparecido de la esfera jurídica: ni de su imaginario ni de su racionalización; está presente en el lenguaje del legislador, de jueces y juristas. Los juristas de la tradición "continental"" la analizan constantemente 9

${ }^{6}$ Así: CHEvrier, Georges, "Remarques sur l'introduction et les vicissitudes de la distinction du «jus privatum» et du «jus publicum» dans les œuvres des anciens juristes français”, Archives de philosophie du droit, 1952, p. 7.

${ }^{7}$ Es el caso de Domat, Jean, Les quatre livres du droit public, Caen, Paris, 1989, entre otros.

${ }^{8}$ Troper, Michel, Pour une théorie juridique de l'État, Presses Universitaires de France, París, 1994, p. 184: «la distinction droit public-droit privé et la structure de l'ordre juridique», quien sigue a KeLSEN. La distinción pareciera no tener relevancia en el Common Law, en el Derecho anglosajón. Vid. OLIVER, Dawn, "Pourquoi n'y a-t-il pas vraiment de distinction entre droit public et droit prive en Angleterre?", Revue internationale de droit comparé, 2001, $\mathrm{N}^{\circ}$ 2, quien señala que "no existe más que el derecho y la justicia", y Auby, Jean-Bernard y FreEDLAND, Mark, La distinction du droit public et du droit privé: regards francais et britanniques, LGDJ Diffuseur, París, 2004, que contiene las actas de un encuentro franco-británico de profesores de distintas especialidades, dirigido a analizar la dicotomía en los dos sistemas.

${ }^{9}$ Es posible reenviar a cada manual introductorio de las disciplinas del Derecho, o de filosofía o teoría del Derecho. La bibliografía podría ser amplísima. Para nuestros efectos actuales, podemos constatarlo en: Radbruch, Gustav, Filosofía del derecho, Comares, Granada, 1999, pp. 159-164, §16. "Derecho público y privado", (trad. José Medina Echevarría); Boвbio, Norberto, Estado, Gobierno y Sociedad, Fondo de Cultura Económica, México, 2004, pp. 11-38, I. "La gran dicotomía: público / privado"; Desmons, Éric, "Droit privé, droit public", en Alland, D.; Rials, S. (Coords.), Dictionnaire de la culture juridique, Quadrige-Lamy, PUF, París, 2003, pp. 520-525. Para Chile, el señero intento de CésPedes Proto, Rodrigo, "La clasificación del derecho en público y privado en el ordenamiento jurídico chileno", Actualidad 
y ha sido objeto de una intensa discusión. ${ }^{10}$

Existe paralelamente una tradición de filósofos que acogen, analizan y promueven la partitio; así, desde la perspectiva de la filosofía y la sociología es aceptada desde el siglo XVIII por autores célebres: Montesquieu, Rousseau, Hegel, Kant, Weber, Hayek. ${ }^{11}$ Existen además quienes niegan la distinción, tildándola de ideológica y anticientífica, ${ }^{12}$ hasta los que la relativizan; ${ }^{13}$ todo lo cual tiene un trasfondo ideológico, discusión que no podemos abordar aquí.

Desde la perspectiva del método jurídico existen quienes la promueven; en esta línea podemos mencionar dos notables juristas de la tradición jurídica hermenéutica, quienes, en páginas suyas famosas, valoran la distinción. Así, por una parte, en el siglo XIX, Friedrich Karl von Savigny, fundador de la escuela histórica del derecho e identificador del Volkgeist, la trata de manera expresa, como dividiendo el sistema jurídico todo. ${ }^{14}$ Por otra, a fines del siglo

Jurídica (Universidad del Desarrollo), 2004, № 9, pp. 273-300.

${ }^{10}$ Véase el análisis realizado desde la tradición anglosajona por: MERryman, John Henry y Pérez-Perdomo, Rogelio, The Civil Law Tradition, Stanford University Press, Stanford, California, 2019, 4ta ed., §14: Legal Categories, pp. 93-103, para quienes es la división principal de la tradición del derecho civil. Véase la edición castellana de la $1^{\circ}$ edición en inglés de 1969: Merryman, John Henry, La tradición jurídica romano-canónica, Fondo de Cultura Económica, México, 1971, pp. 172-190.

${ }^{11}$ Véase en sus obras: MonTesquieu, L'Esprit des lois, Garnier, París, 2011, vol. 2, Libro XXVI, capítulo XVI: "No hay que decidir por las reglas del derecho civil cuando se trata de decidir por las de derecho político"; Rousseau, Jean-Jacques, Du contrat social, Tecnos, Madrid, 1995, pp. 53-54, libro II, capítulo XII: División de las leyes. Las divide en: políticas, civiles y criminales; Hegel, Friedrich, Principios de la Filosofia del derecho, Edhasa, Madrid, 1999, pp. 370 y ss., no se refiere a público/privado directamente, sino a derecho abstracto (pp. 117 y ss.) y a derecho político; subordina la esfera del derecho privado al poder del estado (derecho político), § 261, quien cita a MoNTESQUIEU; KANT, Inmanuel, La metafísica de las costumbres, Tecnos, Madrid, 1989, pp. 54 y ss. [intitulan sus 1 1. y 2 ${ }^{\mathrm{a}}$. partes.]; WeBER, Max, Sociología del derecho, Comares, Granada, 2001, pp. 3-23 ("la diferenciación de los campos jurídicos objetivos"); HAYEK, Friedrich, Law, Legislation and Liberty, Routledge, Londres, 1973, vol. 2, pp. 228-252.

${ }^{12}$ Es el caso de la posición positivista normativista que niega la distinción, a partir de Kelsen, Hans, Teoría general del Estado, Comares, Granada, 2002, pp. 133-153, § 17. Derecho público y privado.

${ }^{13}$ Un panorama y amplia bibliografía puede verse en Pugliatti, Salvatore, "Diritto pubblico e diritto privatto", en: F. CALASSO (ed.), Enciclopedia del diritto, Giuffrè editore, Milán, 1958, XII, pp. 606-746; DAVID, Rene, Los grandes sistemas jurídicos contemporáneos, Aguilar, Madrid, 1968, pp. 62-64, 150, 196, 262-263; De Béchillon, Denys, Qu'est-ce qu'une régle de Droit?, Editions Odile Jacob, Paris, 1997, pp. 40 y 72; Geuss, Raymond, Public Goods, Private Goods, University Press, Princeton, 2003 passim; Hirschman, Albert, Interés privado y acción pública, Fondo de Cultura Económica, México, 1986; SACCo, Rodolfo, Antropologia giuridica, il Mulino, Bolonia, 2007, pp. 237-246.

${ }^{14}$ Vid. SAVIGNY, Friedrich Karl, Sistema del derecho romano actual, Editorial Comares, Granada, 2005, I, $\S 9$. 
XX, Ronald Dworkin trata la divisio como prioridad local, asignándole un papel central en la conformación del pensamiento jurídico, ${ }^{15}$ según Dworkin la división del derecho en departamentos separados es una característica prominente de la práctica jurídica, y entre tales divisiones menciona la que divide el derecho en derecho privado y derecho público. ${ }^{16}$

Todo lo anterior explica la constante presencia de la dicotomía en nuestra cultura.

\section{La dualidad público / privado ante el derecho comparado}

Si revisamos el panorama en Europa, Inglaterra y Latinoamérica nos encontramos con la siguiente situación en cuanto a la literatura:

a) en Europa la discusión es abundante y está vinculada a la existencia de la dualidad jurisdiccional: i) el caso paradigmático es el derecho francés, que a partir del famoso arrêt Blanco de 1873 dio origen a la dualidad jurisdiccional; esto es, al nacimiento del contencioso administrativo separado de la jurisdicción civil y penal. Esta dualidad origina la existencia de jueces especializados para casos de derecho privado, por un lado; y de derecho público (= derecho administrativo), por otro $;{ }^{17}$ ii) en términos

\footnotetext{
${ }^{15}$ Vid. Dworkin, Ronald, Law's Empire, Harvard University Press, Cambridge, 1986, pp. 250-251 (“private from public law"); en la trad. castellana: El imperio de la justicia, Gedisa, Barcelona, 1988, pp.180-181.

${ }^{16}$ Dice Dworkin cit. (n. 15): "[L]os argumentos legales y judiciales respetan estas divisiones tradicionales". Esta constatación de Dworkin la realiza en medio del análisis de "la integridad del derecho", y este planteamiento, en su obra, es posterior y complementario a su más famosa propuesta: la separación de reglas y principios. Dicho autor se refiere a los que llama distintos departements of law (traducido usualmente como "departamentos" del derecho), los que conformarían la división del derecho: compartmentalization of law. Es evidente la referencia de Dworkin a lo que en nuestra tradición denominamos división de disciplinas especializadas o ramas del derecho, como es el caso de lo público/ privado. En el Index de Law's Empire, donde está este desarrollo, el autor destaca esta materia bajo ese significante: compartmentalization; en el Índice temático de la traducción castellana se elige el curioso significante "divisionismo [sic] del derecho", dando la impresión de que la división del derecho fuese una tendencia discutida o materia disputada; debemos considerar mejor, siguiendo el original: o división o compartimentalización del derecho.
}

${ }^{17}$ La bibliografía es casi inabarcable y los conflictos parten desde los manuales clásicos. Véase: HAuRIou, Maurice, Précis de droit administratif et de droit public, Dalloz, Paris, 2002, quien la acogía, y Duguit, León, Manual de Derecho Constitucional, Comares, Granada, 2005, quien la negaba; luego en los textos más modernos de BÉNOIT, Francis-Paul, Le droit administratiffrançais, Dalloz, París, 1968 ; ChAPus, René, Droit administratif général, Montchestien, Paris, 2000; Gaudemet, Yves, Droit amministratif général, LGDJ, Paris, T.1, 2001; Dupuss, Georges, Droit administratif, Sirey, Paris, 2007; GonoD, Pascale, Traité de droit administratif, Dalloz, París, T. 1, 2011; Malaurie, Philippe, Droit Civil. Introduction générale, 
similares opera el derecho belga, a raíz de la dualidad jurisdiccional; ${ }^{18}$ iii) igualmente en el caso suizo, cuya dualidad jurisdiccional ha originado un gran interés por la partitio ${ }^{19}$ iv) en derecho italiano, de igual modo el fenómeno ha sido ampliamente analizado, dada su dualidad jurisdiccional $;{ }^{20} \mathrm{v}$ ) en derecho

Defrénois, Paris, 2005, pp. 47-54; y ahora último en el monumental debido a Plessix, Benoît, Droit administratif général, LexisNexis, París, 2016. Ver igualmente los estudios monográficos de: AuBY, cit. (n. 8), BARRAUD, Boris, "Droit public - droit privé: de la summa divisio à la ratio divisio?" Revue de la recherche Juridique - Droit Prospectif, 2014; TuSSEAu, Guillaume, "Le dualisme juridique", en: BIENvEnu, J.J. ; Petit, J. ; Plessix, B.; Seiller, B. (dirs.), La Constitution administrative de la France, Dalloz, Paris, 2012, pp. 35-48 [quien propone y analiza como art. $2^{\circ}$ de una supuesta constitución administrativa el siguiente: «Las relaciones de derecho son, sea de derecho público o de derecho privado, en consideración a la naturaleza de los sujetos de derecho, de las actividades y de las situaciones"]; BIGOT, Grégoire, "La difficile distinction droit public/droit privé dans l'ancien droit: l'exemple du droit administratif', Droits, 2003, Nº 38, pp. 97-111; Broy, Xavier, L'identité du droit public, ICapitole-LGDJ, Presses de l'Université Toulouse, Toulouse, 2011; Bonnet, Baptiste, De l'intérêt de la summa divisio droit public-droit privé ?, Dalloz, París, 2010; Chamard, Caroline, La distinction des biens public et des biens privés. Constitution à la définition de la notion de biens publics, Dalloz, Paris, 2004; Gaudemet, Yves; Gaudemet, Sophie, "Droit public, droit privé", Revue de droit Henri Capitant, 2012, N5 ; PaPaefthymiou, Sophie, "La distinction «droit privé-droit public» en France entre 1848 et 1900: le paradigme positiviste perdu", Annales de la Faculté de Droit de Strasbourg, Nouvelle Série, 1997, № 1, pp. 101-133; y, especialmente, la tesis de Plessix, Benoît, L'utilisation du droit civil dans l'elaboration du droit administratif, Editions Panthéon-Assas, París, 2003. Cabe agregar las tesis de: CAmus, Clotilde, La distinction du droit public et du droit privé et le conflit de lois, LGDJ - l'extenso éditions París, 2015; y de BouILLon, Henri, Recherche sur la définition du droit public, IRJS Éditions [Institut de recherche juridique de la Sorbonne], 2018. En fin, la colectánea : Alvazzi del Frate, Paolo; Bloquet, Sylvain y Vergne, Arnaud, La summa divisio droit public/droit privé dans l'histoire des systèmes juridiques es Europe (XIXe.-XXIe. siècles), Institut Universitaire Varenne, París, 2018.

${ }^{18}$ Vid.: Ommeslaghe, van, P., "Le droit public existe-t-il?" Revue de la Faculté de droit, Université libre de Bruxelles, 2006, vol. 33, I, pp. 15 y ss. y el reciente de VAn Meerbeeck, Jérémie, "Droit public et droit privé: ni summa ni divisio?", La distinction entre droit public et droit privé. Pertinence, influences croisées et questions transversales, Anthemis, Limal, 2019, pp. 9-76.

19 Véase los completos manuales de Dubey, Jacques y ZufFerey, Jean-Baptiste, Droit administratif générale. Helbing Lichtenhahn, Bâle, 2014, pp. 70-92 y, en especial de Moor, Pierre, Droit Administratif. Volume I: Les fondements généraux, Berna, Editions Staempfli, 3a. ed., vol I, 2012 pp. 92-124.

${ }^{20}$ Desde los textos históricos de Nocera, cit. (n. 4) y crítico de IrTI, Natalino, La edad de la descodificación, Bosch, Barcelona, 1992, pp. 43-84, a los propiamente administrativos de: ZanoBINI, Guido, Corso di Diritto Amministrativo, Giuffré, Milán, 1958, T I, pp. 23-26, CAssese, Sabino, "Diritto privato / diritto pubblico: tradizione, mito o realtà?", en Conte, G.; Fusaro, A.; Somma, A.; Zeno Zencovich, V. (dirs.), Dialoghi con Guido Alpa, Roma Tre Press, Roma, 2018, pp. 51-56; Cerulli, Vincenzo, Amministrazione pubblica e dirritto privato, Giappichelli, Turín, 2000; Cerulli, Vincenzo, Lineamenti del diritto amministrativo. Giappichelli, Turín, 2006, pp. 6-7; SoRDI, Bernardo, "Verso la grande dicotomia: il percorso italiano", Quaderni fiorentini per la storia del pensiero giuridico moderno, 2016, Vol. XLV, pp. 193-209; SoRDI, Bernardo, Public Law before "Public Law", Oxford University Press, Oxford, 2018; SordI, Bernardo, Oltre la dicotomia tra pubblico e privato: le origini del diritto sociale, Vita e Pensiero, Milano, 2018. 
alemán es especialmente relevante la dicotomía público / privado por la dualidad jurisdiccional; ${ }^{21} \mathrm{y}$, en fin, vi) el caso del derecho español es especial, pues a pesar de su modelo mixto, pero más bien de unidad jurisdiccional, es bien relevante la partitio. ${ }^{22}$

b) El tema paradojalmente también ha interesado en derecho inglés, aunque sea el paradigma de la jurisdicción unitaria, hoy relativizada con algunas instancias especializadas. ${ }^{23}$

${ }^{21}$ Puede verse la discusión clásica de fines del siglo XIX y principios del siglo XX en: Gerber, C. F. von, Ueber öffentliche Rechte (Tübingen), Giuffré, Milán, 1852, pp. 29-45; JELLINEK, Giorgio, System der subjektiven öffentlichen rechte, Mohr Siebeck, Freiburg, 1892; MAYER, Otto, Derecho Administrativo Alemán, Depalma, Buenos Aires, Parte general, T I, 1949, pp. 181-195, y MerkL, Adolf, Teoría general del derecho Administrativo, Comares, Granada, 2004, pp.104-110. Ello en el retrato de StolleIs, Michael, Histoire du droit public en Allemagne. La théorie du droit public impérial et la science de la police 1660-1800, Presses Universitaires de France, París, 1998, pp. 79-111. En los manuales de STERn, Klaus, Derecho del Estado de la república Federal Alemana, Centro de Estudios Constitucionales, Madrid, 1987, pp. 106-110, en el hoy más difundido de MAURER, Hartmut, Derecho administrativo. Parte general, Marcial Pons, Madrid, 2011, 82-103, en el análisis de sistema de Schmidt-Assmann, Eberhard, La teoría general del derecho administrativo como sistema, Marcial Pons, Madrid, 2003, pp. 293-298, y de este último en su reciente trabajo, SCHMIDT-Assmann, Eberhard, "Reflexiones sobre la distinción entre derecho público y derecho privado", Revista de Derecho Administrativo Económico, 2019, №30, pp. 233-243. Hay monografías famosas, partiendo por la de Bullinger, Martin, Derecho público y derecho privado, Olejnik, Santiago, 2018 (trad. de la edición de 1968), véase además: GRIMm, Dieter, Sobre la identidad del derecho público, Centro de estudios políticos y constitucionales, Fundación Coloquio Jurídico Europeo, Madrid, 2015; Huber, Peter, "Die Demontage des öffentlichen Rechts", in: KLuth, W., Müller, M. (Author), Wirtschaft - Verwaltung - Recht: Festschrift für Rolf Stober, Heymanns, Köln, 2008 y HesSE, Konrad 199, Derecho Constitucional y derecho privado, Civitas, Madrid, pp.75-79.

${ }^{22}$ Veáse la discusión, por todos, en los señeros manuales de García DE ENTERRÍA, Eduardo y FernándEZ, Tomás-Ramón, Curso de Derecho Administrativo, Civitas, Madrid, 2012, T. I, y GonzÁLEz, Francisco, Derecho Administrativo Español, Eunsa, Pamplona, 1993. Luego las monografías de: ARCE y FLoresVAldés, Joaquín, Derecho civil constitucional, Civitas, Madrid, 1986; Desdentado Daroca, Eva, La crisis de identidad del Derecho Administrativo: privatización, huida de la regulación pública y Administraciones independientes, Tirant lo Blanch, Madrid, 1999; Malaret i García, Elisenda, Derecho público y derecho privado en la actuación de la Administración Pública, Marcial Pons, Madrid, 1999; MARTínez LóPEZ-MuÑIz, José Luis, "Derecho público y derecho privado, disyuntiva determinante para el Estado de Derecho", Revista de Derecho Administrativo, N4, pp. 91-128; Martín-Retortillo, Sebastián, El derecho civil en la génesis del derecho administrativo y de sus instituciones, Civitas, Madrid, 1996 [ésta muy relevante en la materia]; RIVERo ORTEGA, Ricardo, Administraciones públicas y derecho privado, Marcial Pons, Madrid, 1998; RocA, María J. (coord.), Derecho público y derecho privado. Diferencias de régimen jurídico y cuestiones actuales de recíproca influencia, Iustel, Madrid, 2015; últimamente, Velasco Caballero, Francisco, Derecho público más derecho privado, Marcial Pons, Madrid, 2014; y Barnes, Javier, "An Expanding Frontier of Administrative Law: The Public Life of Private Actors (A Functional Approach)", European Public Law, 2018, Vol. 24, № 3, pp. 595-612.

${ }^{23}$ Véase las importantes colectáneas y monografías de: Allison, J., A Continental Distinction in the Common Law: A Historical and Comparative Perspective, Oxford University Press, 2000; AuBY y 
c) En fin, la preocupación es menor en Latinoamérica, pero existe en el último tiempo algún interés por su análisis. ${ }^{24}$

Como se ve, en especial en Europa, existe un gran desarrollo legislativo, jurisprudencial y doctrinario sobre la dicotomía muy distante de la situación chilena, como muestro supra.

\section{La dualidad jurisdiccional como reflejo de la dicotomía}

Hay más propuestas y amplias discusiones sobre la dicotomía en aquellos países en que existe dualidad jurisdiccional, a raíz de lo cual en la praxis es muy relevante la distinción, dada su conexión con la conformación de las competencias de los tribunales a través de cortes especializadas tanto, por una parte, en el derecho privado (derecho civil y penal) como, por otro, en derecho público (derecho administrativo). La creación de tribunales del contencioso administrativo constituye una dualidad jurisdiccional y es indudablemente un reflejo de la dicotomía.

a) Público y privado y dualidad jurisdiccional. En efecto, en los países en que existe dualidad jurisdiccional (Alemania, Suiza, Francia, por ejemplo) la summa divisio entre lo privado y lo público es crucial a efectos prácticos de interposición de acciones y de la competencia de los tribunales respectivos. Eso explica la amplia bibliografía que ofrece la doctrina (vid. supra), dada la necesidad de que los justiciables tengan claridad al respecto.

b) Jurisdicción unitariaynoespecialparalocontencioso-administrativo. La dualidad jurisdiccional no ha sido el caso de Chile, en lo cual se sigue una

Freedland cit. (n. 8), Oliver, Dawn, Common Values and the Public-Private Divide, Butterworths, London, 1999 cit. (n. 8), y Passerin D’Entreves, Maurizio y Vogel, Ursula (dir.), Public \& Private. Legal, Political and philosophical perspectives, Routledge, Londres y Nueva York, 2000; y RuFferT, Matthias, The Public-private Law Divide: Potential for Transformation? British Institute of International and Comparative Law, London, 2009.

${ }^{24}$ Véase, para Argentina: Viale, Claudio Martín (Dir.), Derecho común y derecho administrativo. Diferencias y contactos, Lerner editores, Buenos Aires, 2009, y Balbín, Carlos F., Impacto del Código Civil y Comercial en el derecho administrativo, Astrea, Buenos Aires, 2016; para Brasil: GARCIA VITTA, Heraldo, Aspectos da teoria geral no direito administrativo, Malheiros editores, São Paulo, 2001 y Bacellar Filho, Romeu Felipe, Direito Administrativo e o novo Código Civil, Editora Fórum, Belo Horizonte, 2007; y para Colombia: CoRTÉs MonCAYo, Édgar, "Derecho privado y derecho público. Una summa divisio entre tradición y adaptación”, en: SCHIPANI, S.; CoRTÉs, E. (coords.), Sistema jurídico romanista y subsistema jurídico latinoamericano, Universidad Externado de Colombia, Bogotá, 2013, pp. 37-51. 
senda británica, como podríamos decir; en efecto, existe unidad jurisdiccional (no hay tribunales del contencioso administrativo con competencia general y supletoria), unidad que se ha roto levemente en los últimos diez años a raíz de la creación de algunos tribunales administrativos hiper especializados en contratación pública, medio ambiente, energía, impuestos (listado en el que podemos agregar la transparencia, dada la función jurisdiccional del Consejo para la Transparencia). En efecto, en Chile la CPR abandonó (no sabemos si definitivamente) en 1989 el antiguo e incumplido encargo al legislador de crear tribunales especiales para lo público (=contencioso administrativo), a la cabeza de un orden jurisdiccional separado de los demás tribunales (como en la mayoría de los países de la tradición continental). Así, hasta ahora los tribunales ordinarios que integran el Poder Judicial ejercen la plenitud de la jurisdicción contenciosa administrativa, de modo supletorio y general, ante la inexistencia de tribunales especiales de lo contencioso administrativo con competencia separada. El conocimiento de toda acción administrativa que no tenga asignado un procedimiento o un tribunal especial, está confiado a los tribunales que integran el Poder Judicial, lo que origina que toda esa jurisdicción ordinaria, cuyos jueces están habituados a conocer y fallar casos de derecho privado (civiles, en la terminología procesal y de la praxis) son llamados en algunas ocasiones a conocer también casos de derecho público (administrativo, en estricto rigor). Aclaración esta que parece inexcusable antes de analizar el panorama de la dicotomía público / privado en las fuentes de derecho chileno.

\section{LA DICOTOMIA PÚBLICO/PRIVADO EN LA NORMATIVA: CONSTITUCIÓN Y LEGISLACIÓN}

En el corpus normativo vigente intento verificar la presencia de la partitio $\mathrm{y}$, desde ahí, intentar aplicar el instrumental dogmático de análisis normativo, identificando eventuales supletoriedades ordenadas por el legislador, las que pueden llegar a establecer verdaderos deslizamientos territoriales desde el derecho privado al derecho público o viceversa. El análisis normativo es la primera observación a las fuentes que cabe realizar; se centra tanto en la Constitución como en las leyes. 
a) La constitucionalización de la división público / privado

La Constitución recoge la partitio. Veamos:

i) La distinción se manifiesta de forma patente. En efecto, se consagra en varios de sus artículos, de modo implícito pero evidente. Desde ya el art. $19 \mathrm{~N}^{\circ} 23$ CPR consagra una summa divisio de los bienes, lo cual es un ejemplo paradigmático de la distinción público/privado. Pero la distinción aparece a cada paso en la CPR; así: distingue los sectores público y privado en los conflictos laborales (art. 60 inc. $4^{\circ}$ ); en las normas de seguridad social (art. $65 \mathrm{n}^{\circ}$ ); ; en establecimientos educaciones (art.142 inc. penúltimo); distingue los trabajadores de ambos sectores $\left(65 \mathrm{~N}^{\circ} 4\right)$; se refiere a las fundaciones "de derecho privado" (art. 118) que presupone las privadas; a entidades de ambos sectores (art. 109 inc. $1^{\circ}$ ); o en fin, a instituciones de ambos sectores (arts. $19 \mathrm{~N}^{\circ} 9$ y $19 \mathrm{~N}^{\circ} 18$ ). Se refiere también la CPR a la personalidad jurídica "de derecho público" de gobiernos regionales y municipios (arts. 111 y 118 inc. $4^{\circ}$ ), lo que presupone la personalidad "de derecho privado". Como se ve, está plagada de referencias a lo público y a lo privado.

ii) Separación de lo estatal y lo privado. Otro giro sinónimo, pero referido a la bipolaridad, utilizando otras expresiones, es aquel que separa lo estatal de lo privado. Se observa en la CPR a propósito de los sistemas de salud (art.19 $\mathrm{N}^{\circ} 9$ inc. $5^{\circ}$ ) o intereses en las peticiones a la autoridad (art.19 $\mathrm{N}^{\circ} 14$ ). A veces se refiere a la partición con las expresiones Estado/ particulares; así en los daños (art. $53 \mathrm{n}^{\circ} 1$ inc. $5^{\circ}$ in fine). O la referencia a la "legislación común aplicable a los particulares" (art.19N²1inc. $2^{\circ}$ ) o a las "normas comunes aplicables a los particulares" (art.115 inc. $5^{\circ}$ in fine). Estos dos giros son bien significativos respecto de la posible sinonimia entre la expresión derecho común y código civil o código del trabajo, por ejemplo. Las empresas "públicas" (art. 115 inc. $5^{\circ}$ ) que presuponen la existencia de las "privadas". En fin, la referencia a intereses "particulares" (art. 134 inc. $4^{\circ}$ ) que presupone su contrario: los intereses públicos o generales.

iii) Opción del legislador respecto de la dicotomía. La CPR no limita al legislador en su opción por regular de manera cruzada la actuación de entidades públicas con normas de derecho privado; o viceversa, la actuación de entidades privadas con normas de derecho público, como por ejemplo (parafraseando el art. $19 \mathrm{~N}^{\circ} 21 \mathrm{CPR}$ ) aplicar a entes públicos las normas "comunes aplicables a los particulares", o viceversa, salvo que ello quebrantara algún designio constitucional sustantivo. 
b) La partitio en la legislación

Observo en especial la partitio en el Código Civil y en los dos cuerpos legales más recientes, de 1991 y 2003, citados al inicio.

i) La partitio en el Código Civil. Desde 1857 el Código Civil señala en su art.547 inc. $2^{\circ}$ lo siguiente:

"Tampoco se extienden las disposiciones de este título a las corporaciones o fundaciones de derecho público, como la nación, el fisco (...)”. [el destacado es agregado]

Asimismo, el art. 1462 del Código Civil establece:

"Hay un objeto ilícito en todo lo que contraviene el derecho público chileno (...)”. [destacado agregado]

Además, ese código está plagado con la expresión "público" (como contrapuesta a lo particular); así, en materia de bienes, los califica como públicos y entre ellos los caminos públicos (art. 589) o de prescripción (art. 2497, en que lo público se hace sinónimo de la expresión "nacional"). Un listado que completa las disposiciones de ese código referidas a la dicotomía es el siguiente: arts. 192 (instrumento "público o privado"); 592 inc. 2 (uso "público" de los bienes de particulares; 595 (aguas como "bienes nacionales de uso público"); 598 (caminos "públicos” y "uso público”); 839 (contrapone uso "público" con la utilidad de "particulares"); 847 (camino "público"); 879 ("camino público o vecinal"; los hace sinónimos); 948 (lugares de uso "público"); 1.105 (cosas de "propiedad nacional o municipal y de uso público"); 1250 (establecimientos "públicos"); 1467 (orden "público"). En fin, especial mención merece el art. 2497 del Código Civil, el que contrapone lo "estatal" de lo "particular", al señalar que:

"Las reglas relativas a la prescripción se aplican igualmente a favor y en contra del Estado, de las iglesias, de las municipalidades, de los establecimientos y corporaciones nacionales, y de los individuos particulares que tienen la libre administración de lo suyo". 
Como reviso más adelante, esta es una disposición mixta pues se aplica tanto a personas jurídicas de derecho público (el "Estado" y otras que menciona) como a personas de derecho privado ("individuos particulares", dice), sujetos que habitualmente operan según normas situadas en polos contrapuestos de la partitio.

ii) Otras leyes. Existen múltiples leyes (de cuya cita específica me excuso, por el volumen que ello significaría) posteriores al Código Civil, que se refieren tanto a las expresiones "público" como "privado" como contrapuestas; o a sus usuales sinonimias: "nacional", "estatal”, por un lado, o "particular" o "individual", por otro. ${ }^{25}$

iii) El epitome del reconocimiento de la dicotomía son dos leyes de 1991 y 2003. El caso en que la partitio completa se transforma en derecho vigente (y ya deja de ser un enunciado histórico, referencial, parcial, implícito o meramente doctrinario) se produce en esas dos leyes de naturaleza administrativa mencionadas en la Introducción: los arts.21 del DFL 164 de 1991 y $1^{\circ}$ de la Ley 19.886 de 2004 , cuyos mandatos obligan al intérprete a identificar las normas de derecho público, lo que presupone igualmente distinguirlas de aquellas de derecho privado, para así aplicarlas del modo y en el orden de prelación que ahí se establece para cada caso.

c) Sólo existen normas públicas o privadas, ¿o también mixtas? Todo lo anterior sin perjuicio de que pueda haber reglas comunes para ambos polos del derecho, esto es, mixtas. Es el caso del art.2497 del CC, aplicable tanto a órganos del Estado (públicos) como a particulares (privados).

\section{LA DICOTOMÍA PÚBLICO / PRIVADO ANTE LA JURISPRUDENCIA: REVISIÓN EN DIEZ TEMAS RELEVANTES DE LA PRAXIS DEL DERECHO ADMINISTRATIVO ${ }^{26}$}

Es relevante la respuesta jurisprudencial en todos los casos en que es visible el uso instrumental de la dicotomía, fijando la mirada no sólo en las tendencias de la jurisprudencia en cada materia, sino en especial sus técnicas.

\footnotetext{
${ }^{25}$ Por ejemplo, la propia Ley N 19.886, de 2003, referida a la contratación "pública" (lo que presupone la contratación "privada" sujeta al Código Civil.

${ }^{26}$ Los casos mencionados en el presente capítulo, se encuentran referenciados en el listado de jurisprudencia al final del artículo.
} 
La dicotomía público / privado ha estado presente en la jurisprudencia, esto es, en la adjudicación del derecho; la actitud usual es la transposición de normas desde uno a otro sector de la partitio, utilizando habitualmente la técnica de la supletoriedad, más o menos nítidamente, más o menos veladamente. A continuación, expongo una casuística de aplicación de la legislación privada (civil, laboral y penal) a casos administrativos, en la cual es se observa la dicotomía. Caracterizo las tendencias que han surgido a raíz de la misma e identifico la anunciada técnica usualmente utilizada por la jurisprudencia: la supletoriedad. Usualmente, como se ve en estos diez temas, se trata de hipótesis típicas de ausencia de norma expresa (lagunas normativas).

1. Cómputo del plazo para que la Administración ejerza la potestad sancionatoria: ¿Aplicación del Código Civil o del Código Penal?

La Corte Suprema (CS) ante el vacío normativo respecto a esta materia propia del derecho administrativo (de una potestad administrativa, como es la sancionatoria), ha debatido sobre la pertinencia de aplicar las normas de la prescripción contenidas en el Código Civil (CC) para resolver sobre el plazo que tiene la Administración para perseguir a los administrados cuando han infringido las normas. Existen dos tendencias:

i) Una tendencia sostiene que dada la raíz común del llamado derecho administrativo sancionador con el Derecho Penal deben aplicarse las normas de los arts. 94 y 97 del Código Penal (CP). Dice la CS que no es posible aplicar supletoriamente la norma del art. 2515 del CC sobre prescripciones de largo plazo, producto de las distintas naturalezas presentes en dichas normas, toda vez que el primero se encuentra dentro del ámbito del derecho público y, el segundo, se ve inspirado por principios jurídicos pertenecientes al orden privado, regulados precisamente en el Código Civil. Esta tendencia se sigue en los casos: Empresa Eléctrica Antofagasta (2009), Empresa Eléctrica Aysén (2009), Weinstein (2010), Weinstein (2011), Laboratorios Recalcine S.A. (2011), Martins (2012), ISP con Laboratorio Bestpharma (2012), ISP con Laboratorios Recalcine (2012), Laboratorios Recalcine con ISP A (2013), Laboratorios Recalcine con ISP B (2013), DGA con Alto Atacama (2013), Industria Frigorifica (2014), Forestal (2015), Fisco con Ferrcentro (2017). Se ha manifestado también en las disidencias y prevenciones de los integrantes de la Sala en los casos Promaq (2017), Pharmamérica (2017), 
Isapre Cruz Blanca (2017), Casino de Juegos (2018), Fisco con Yáñez (2018), Banco de Chile (2018), Montexchgange (2018), Minera Zaldivar (2018), Laboratorios Lafi A (2018) y Laboratorios Lafi B (2018), Opko (2019) y Laboratorios Pharma (2019).

ii) La segunda tendencia, consolidada en el último tiempo, considera que es necesario acudir a las "normas generales del derecho común dentro del ámbito civil y, en ese entendido, hacer aplicación de la regla general de prescripción extintiva de 5 años a que se refiere el art. 2515 del CC". Esta tendencia se sigue en los casos Albala (2015), Farah (2016), Promaq (2017), Pharmamérica (2017), Isapre Cruz Blanca (2017), Casino de Juegos (2018), Fisco con Yáñez (2018), Banco de Chile (2018), Montexchange (2018), Roig (2018), Minera Zaldivar (2018), Laboratorios Lafi A (2018) y Laboratorios Lafi B (2018), Opko (2019) y Laboratorios Pharma (2019). También se manifiesta en las disidencias y prevenciones, principalmente del ministro Pierry en Empresa Eléctrica Aysén (2009), Empresa Eléctrica Antofagasta (2009), Empresa Eléctrica Aysén (2009), Weinstein (2010), Weinstein (2011), Martins (2012), ISP con Laboratorio Bestpharma (2012), ISP con Laboratorios Recalcine (2012), Laboratorios Recalcine con ISP A (2013), Industria Frigorifica (2014) y Forestal (2015).

2. Plazo de prescripción de la acción de nulidad administrativa: Aplicación del Código Civil

Nuevamente, las normas del CC son utilizadas por la CS para rellenar una laguna normativa del derecho administrativo, lo que ha generado dos tendencias:

i) La línea mayoritaria distingue entre acciones destinadas a obtener la nulidad del acto y las declarativas de derechos o de plena jurisdicción, sosteniendo que la acción que prescribe es la acción del particular cuando esta tiene un componente patrimonial (la de plena jurisdicción). Por lo anterior, en el caso de las acciones de plena jurisdicción la CS estima que "se encuentran sometidas, en lo concerniente a la prescripción, a las reglas generales contempladas en el CC, entre otras, a las disposiciones de sus artículos 2497, 2514 y 2515". Esta tendencia se sigue en los casos INP I (2008), INP II (2008), INP III (2008), INP (2009), Le Roy (2009), Espinosa (2009), INP (2010), Comunidad (2011), Peñablanca (2012), Vila (2012), Droguett (2013), Gardilcic (2013), Flores (2014), Inmobiliaria Las Delicias 
(2014), Senerman (2014), EMCOSER (2014), Castro (2014), Gangas (2014), Pettinelli (2014), Espinoza (2015), Ovalle (2015), Rojas (2015), Mellado (2015), Pinto (2015), González (2015), Ilabaca (2015), Minera Ximenita (2015), Las Delicias (2015), De la Torre (2015), Klein (2015), Pavimentos (2015), Castro (2016), Vio (2016), Fundación (2016), Astaburuaga (2017), Sweet (2018), Pacific Steam (2018), Navarro (2018), Corporación (2018), Los Canelos (2018), Pesquera (2019) у Comunidad (2019).

ii) Otra tendencia se configura en base al art. 7 de la CPR, sosteniendo que toda acción de nulidad administrativa es de derecho público, por consiguiente, la acción de nulidad y sus efectos patrimoniales son imprescriptibles, dado que no le es aplicable la legislación contenida en el derecho privado. Esta línea jurisprudencial se manifiesta en la disidencia del ministro Cerda en el caso Sweet (2018) y, en especial, en la permanente disidencia del ministro Sergio Muñoz en los casos Droguett (2013), Astaburuaga (2017), Sweet (2018), Pesquera (2019) y Comunidad (2019).

3. Plazo de prescripción de la acción indemnizatoria de responsabilidad: Aplicación del Código Civil

La CS, de manera uniforme, ha aplicado el CC ante el vacío normativo; junto a esta tendencia se ha desarrollado una constante disidencia:

i) Según la tendencia uniforme de la CS, la acción indemnizatoria, por falta de servicio que se sigue en contra de los órganos administrativos, prescribe según las normas del $\mathrm{CC}$, de acuerdo al plazo indicado en el art. 2332, esto es, en el término de 4 años, lo que resulta concordante con lo preceptuado por su art. 2497, en tanto señala que las reglas sobre prescripción se aplican igualmente "a favor y en contra del Estado". Esta tendencia se sigue en: Guardia (2012), Klein (2012), Pavez (2012), Richard (2012), González (2014), Fernández (2014), Contreras (2014), Gana (2014), Retamales (2015), Ortiz (2015), Parraguez (2015), Cortes (2015), Muñoz (2015), Cruz Blanca (2015), Viscay (2015), Ramírez (2016), Cortes (2016), Guajardo (2016), Perret (2017), Hernández (2017), Municipalidad de Nueva Imperial (2017), Gutiérrez (2017), Vargas (2017), Rodríguez (2017), Osses (2017), Constructora Orión (2017), Orrego (2017), Mancilla (2018), Erices (2018), Bustamante (2018), Alegría (2019), Alcamino (2019), Laboratorios (2019), Olate (2019) y Báez (2019).

ii) Existe una permanente disidencia sostenida por el ministro Sergio 
Muñoz quien plantea que las normas contenidas en el $\mathrm{CC}$ relativas a la prescripción no son aplicables en materia de acciones indemnizatorias por responsabilidad de la Administración del Estado, toda vez que los principios inspiradores del derecho público no son compatibles con aquellos que se encuentran en el derecho privado. Argumenta, además, que el ordenamiento de naturaleza de derecho público no contempla a la prescripción como sanción de carácter general, por lo que tampoco cabría su aplicación desde esta perspectiva. Esta disidencia se manifiesta en las prevenciones del ministro S. Muñoz en los casos Pavez (2012), Richard (2012), Perret (2017), Municipalidad de Nueva Imperial (2017), Gutiérrez (2017), Vargas (2017), Rodríguez (2017), Osses (2017), Constructora Orión (2017), Orrego (2017), Mancilla (2018) y Erices (2018).

4. Prescripción de la acción indemnizatoria que emana de la ejecución de crímenes de lesa humanidad cometidos por agentes del Estado: ¿Aplicación del Código Civil o de Tratados Internacionales?

La resolución de estos casos ha dependido de la Sala en la que, eventualmente, se resuelven; existiendo dos tendencias: una apegada al tratamiento que hacen los tratados internacionales en esta materia y otra de carácter privatista, en la que se aplican las normas de prescripción del CC (siguiendo la tendencia vista supra 3 ).

i) Una postura postula que dado que la acción penal, en estos casos, es imprescriptible, también debiera serlo la acción patrimonial, con el fin de brindar a las víctimas una reparación integral del daño causado, en concordancia con la normativa internacional sobre la materia, ratificada y vigente en Chile. Esta es la tendencia que se ha consolidado de manera uniforme en la Segunda Sala de la Corte Suprema. Se recurre, así, supletoriamente a un tratado internacional.

ii) La otra tendencia postula que dado el carácter "patrimonial" de la acción de indemnización y ante la ausencia de norma que establezca el plazo de prescripción de esta acción, debiesen aplicarse las normas del derecho común, esto es, el CC, el que señala en su art. 2332 que la acción prescribe en el plazo de 4 años contados desde la perpetración del hecho. Cabe notar que la aplicación de este artículo, situado en el título de los delitos y cuasidelitos del CC, presume la aplicación del mismo a los casos de responsabilidad de la Administración, en especial su art. 2314, que es otra hipótesis de discusión 
en la jurisprudencia. Esta tendencia, ya abandonada, se siguió en los casos Ruz (2008), Vera (2008), Montiel (2008), Negrete (2008), Lillo (2009), Burgos (2009), Rojas (2009), Retamales (2009), Peña (2009), López (2009), Paredes (2009), Pereira (2009), Tenorio (2010), Toro (2010), Fuenzalida (2010), Rosas (2010), Rojas (2010), Sánchez (2010), Tamayo (2011), Nilo (2011), Aldoney (2011), Vera (2011), Quinteros (2011), Zúñiga (2011), Rosales (2012), Segura (2012), Ortiz (2012), Jara (2012), Acevedo (2012), Sotomayor (2012), Cattani (2012), Pablos (2013), González (2013), Coña (2013), Martínez (2013), Millalén (2013), Ponce (2013), Gutiérrez (2013), González (2013), Castro (2013) y Salgado (2014).

5. La responsabilidad patrimonial de la administración: ¿Aplicación del Código Civil o de las normas administrativas especiales?

El art. 2314 CC regula de un modo escueto la responsabilidad por daños y la subsecuente indemnización. Pero, al respecto existen normas de naturaleza administrativa que regulan la cuestión, en especial, arts. 42 de la Ley 18.575/1986 y 142 de la Ley 18695 de Municipalidades. Las acciones de responsabilidad por daños son conocidas por los tribunales ordinarios de justicia que integran el Poder Judicial, ante la inexistencia de tribunales especiales de lo contencioso administrativo con competencia general. Hoy las tendencias jurisprudenciales discuten si aplicar el CC o las leyes especiales administrativas. La CS ha señalado que el factor de imputación en los casos de responsabilidad patrimonial de la administración es la falta de servicio, conforme lo dispone expresamente el artículo 42 de la Ley $\mathrm{N}^{\circ}$ 18.575. La CS resuelve así aplicando una norma de derecho administrativo (y no una norma de derecho civil) en los casos Gatica (2019), Luna (2019), Vera (2019), Leal (2019), Pérez (2019), Fariña (2019), Sepúlveda (2019), Reyes (2019) y Alvial (2019).

6. Nulidad de actos administrativos: ¿Aplicación del Código Civil o de normas constitucionales y especiales administrativas?

En materia de actos administrativos y de su sanción de ineficacia, igualmente se han manifestado ampliamente las tendencias jurisprudenciales advertidas en los casos anteriores, de aplicar ya sea el estatuto propio de derecho público de los actos administrativos o, a veces, intentar aplicar 
supletoriamente las reglas que, sobre nulidad de actos privados, contiene el Código Civil. Una demostración de esto es el caso Central de Abastecimiento (2020), en que se insiste que la nulidad de los actos administrativos se encuentra regulada "por el Derecho público y no por el Código Civil" $\left(\mathrm{c} .5^{\circ}\right)$, y así una larga estela de sentencias anteriores en que se advierte que la colaboración normativa no puede originar incoherencias.

7. Afectación presunta de bienes privados al uso público: Aplicación del Código Civil o de la norma especial administrativa

En este caso el criterio de la jurisprudencia ha dependido de la sala especializada que conozca las causas; en efecto, la Primera Sala [Civil] y la Tercera Sala [Constitucional/Administrativa], ofrecen criterios diferenciados, influidos por esa especialidad. De ahí que el acogimiento de las reclamaciones sobre bienes de propiedad privada presuntamente afectos al uso público ha dependido de la Sala que lo conozca, sin perjuicio de que, a partir del año 2011, todos los casos se radicaron en la Tercera Sala. Así;

i) la Primera Sala no reconoce, de manera alguna, la consagración legal de la afectación presunta contenida en el art. 26 del DFL $\mathrm{N}^{\circ} 850 \mathrm{del}$ MOP. Son de esta Sala los casos Biava (2007) y Ferro (2008); y,

ii) la Tercera Sala reconoce la existencia de la afectación presunta y su consagración en el art. 26 del DFL N ${ }^{\circ} 850$ del MOP. Son de esta Sala los casos Benavides (2011), Novare Agrícola (2013), Labrador (2014), Sociedad Weltgrund (2014), Sociedad Agrícola El Tangue (2015) y Jerez (2017).

8. Funcionarios a honorarios de la administración del Estado: ¿Aplicación del Código Civil, de la norma administrativa o del Código del Trabajo?

Al respecto la CS ha desarrollado dos tendencias:

i) La primera aplica el Estatuto Administrativo o el Estatuto Municipal. Esta tendencia niega la aplicación del Código del Trabajo en virtud de que estos vínculos no se pueden homologar a las relaciones laborales consagradas en el art. 7 Código del Trabajo (CT), por nacer al amparo de los estatutos ya mencionados. Se ha resuelto según esta tendencia en los casos Sánchez (2019), Faúndez (2019) y Canales (2019). 
ii) La segunda califica el vínculo entre la persona natural y el órgano de la administración como relación laboral si se cumple con los supuestos del art. 7 del CT, siendo en tal caso, aplicables las normas del mentado Código. La CS ha fallado conforme a esta tendencia en los casos Morales (2019), Elso (2019), Cerón (2019) y Soto (2019).

9. Tutela laboral deducidas por funcionarios de la Administración: ¿Aplicación de la norma administrativa o del Código del Trabajo?

Antes de una modificación legal que resolvió el problema, ${ }^{27}$ según lo dispuesto en el CT, los trabajadores que veían vulneradas sus garantías fundamentales en el contexto de una relación laboral pueden deducir una demanda de tutela laboral, establecida en su art. 485 y ss. y son los juzgados de letras del trabajo los competentes para conocer de dichos asuntos. ¿Qué ocurría cuando los funcionarios públicos, es decir, aquellas personas naturales que se vinculan con órganos de la Administración en virtud de un vínculo estatutario, ven vulneradas sus garantías fundamentales? ¿Son competentes los juzgados laborales para conocer de estas demandas? El tema generó dos tendencias al interior de la Cuarta Sala de la Corte Suprema.

i) Una tendencia estimaba que los juzgados laborales son competentes para conocer de las tutelas laborales deducidas por funcionarios públicos. Esto, en virtud de que se deben proteger y tutelar los Derechos Fundamentales de estos funcionarios, ya que son de rango constitucional. La CS conforme a esta tendencia en los casos Torres (2017), Zárate (2017), Delgado (2019), Jara (2019) y Tudesca (2019), entre otros.

ii) La otra tendencia considera que los tribunales laborales son incompetentes absolutamente, en razón de la materia, para conocer de una demanda de tutela de derechos fundamentales incoada por una funcionaria pública. Ha fallado en este sentido la CS en el caso Castillo (2011), Hidalgo (2012), Vallejos (2012), Ross (2013), Andrade (2014), Villalobos (2015), Gómez (2015) y Solís (2019).

${ }^{27}$ Cfr. Ley $\mathrm{N}^{\circ} 21.280$, sobre el ámbito de aplicación del procedimiento de tutela laboral, de 2020. 
10. Contratación administrativa: Hipótesis típica en que existe norma expresa que consagra la distinción público / privado

Es una hipótesis distinta a la de los casos anteriores (en que hay vacío normativo), el caso del citado art. $1^{\circ}$ de la Ley $\mathrm{N}^{\mathrm{o}} 18.886$, de bases sobre contratos administrativos de suministro y prestación de servicios, de 2003, el que habilita al juez a acudir a las normas de derecho privado cuando las normas de derecho público no sean suficientes para resolver. Los jueces han entendido que habilita, entonces, a la aplicación del Código Civil por supletoriedad expresa en base a esa norma. Así, la Tercera Sala de la Corte Suprema resolvió en el caso Oscar Inostroza Constructora EIRL (2020), que es correcto aplicar "las normas más elementales que rigen el contrato en el derecho privado, esto es, los artículos 1545 y 1546 del Código Civil" en un caso relativo a un contrato administrativo. Además, en su c. $8^{\circ}$ el fallo señala que: "ante la inexistencia de solución en la normativa de Derecho Público, es ineludible recurrir al primero [derecho privado] ", en este caso se recurre a las normas de Código Civil. Existen fallos anteriores en la misma línea: Sociedad Deportes Palestina (2006), Caballero (2013) y Salas (2015), en los cuales se establece de manera expresa que el máximo tribunal avala la aplicación del art. 1546 del CC en contratos administrativos.

\section{Comentarios a la revisión jurisprudencial}

Al respecto, cabe afirmar:

$1^{\circ}$. La jurisprudencia, suele traspasar la barrera de lo público incorporando soluciones de derecho privado. La jurisprudencia muestra en las variadas temáticas revisadas, la importancia y utilidad práctica de la summa divisio entre lo público y lo privado al momento de resolver aplicar o no la técnica de la supletoriedad, pues lo hace con perfecta conciencia de estar cruzando una frontera.

La jurisprudencia entonces pareciera navegar entre la búsqueda de coherencia y la adecuada colaboración "territorial". Existe un recurso constante a esta técnica de resolución de casos de derecho administrativo recurriendo a códigos del "sector privado", y el juez, antes de fallar, apela a esta partición del derecho, en la búsqueda de argumentos. En todos estos casos cabría analizar si la aplicación de esta técnica no arriesga romper la racionalidad y coherencia de "lo público", o si se trata de una "colaboración" 
normativa adecuada; o, en su caso, definir las técnicas adicionales que cabe sugerir en tales traspasos territoriales. Resta analizar entre nosotros si siempre el resultado jurisprudencial es coherente, en su caso, con la esencia de lo público: esto es, cuando se recurre al Código Civil para fallar un caso de naturaleza administrativa, el juez aquilata adecuadamente que está traspasando una norma civil (que regula relaciones entre privados, que actúan en virtud de la autonomía de la voluntad) hacia el terreno de lo público/administrativo (en que se debe perseguir el interés general o el bien común).

$2^{\circ}$. La jurisprudencia no suele aplicar únicamente el Código Civil sino también otros códigos y leyes por la vía de la supletoriedad. En los casos exhibidos se discute la eventual aplicación del Código Civil a casos de derecho administrativo. Si bien la muestra se centra en los casos en que se disputa la aplicación de ese código, existen otros cuerpos legales del sector del "derecho privado" que se aplican a casos de derecho administrativo: Es el caso, primero, de la aplicación del Código del Trabajo a funcionarios públicos (regidos en general por estatutos administrativos) en las hipótesis de trabajadores a honorarios que prestan servicios en órganos administrativos y de la tutela laboral de estos trabajadores; y, además, es el caso de la aplicación del Código Penal a la prescripción de la acción persecutoria de las sanciones administrativas.

$3^{\circ}$. La jurisprudencia no aplica generalizadamente el CC en temas medulares de derecho administrativo sino en temas bien concretos $y$ secundarios. Existen dos temas medulares del derecho administrativo en torno a los cuales se concentran sus dos grandes contenciosos, los que constituyen sus dos materias capitales: por una parte, la responsabilidad patrimonial de la Administración y, por otra, la nulidad de los actos administrativos. Al respecto, en cuanto al fondo de esos dos temas, en sus aspectos sustantivos, la jurisprudencia aplica de manera consistente únicamente normas y criterios procedentes de actuales normas y principios de derecho público administrativo. Lo mismo en materia de bienes públicos en la sala especializada. Es sólito el rechazo a la aplicación del CC en estos casos nucleares de la disciplina.

Es en materia de contratación administrativa donde con consistencia se aplican normas bien específicas y acotadas del CC, pero ello es así porque existe una norma de derecho administrativo que regula y acepta esa supletoriedad: el art. $1^{\circ}$ de la ley $\mathrm{N}^{\circ} 19.886$ de 2003 . En esta materia hay un 
amplio recurso a diversas normas del CC, y ello es razonable por la similitud del tema contractual en una relación entre privados como en la relación de un órgano administrativo con un particular. Esta supletoriedad se produce sin recurrir a una supuesta regla general de supletoriedad que emanaría del art. $4^{\circ} \mathrm{CC}$, lo que es una demostración de que para aplicar normas del CC en casos de naturaleza administrativa debe existir un mandato expreso de la propia ley administrativa.

En lo que sí existe una intensa aplicación del CC es en algunos temas secundarios, pero importantes en la praxis (revisados supra), como es el cómputo de plazos de prescripción de las acciones judiciales para casos administrativos (tema procesal) y en los conceptos relevantes de esa institución dado que tal materia está regulada sólo en el CC; pero esto no constituye ni un tema ni unas normas relativas a la médula de la disciplina del derecho administrativo. Sin perjuicio de que, en este caso de la prescripción, el Código Civil contiene una norma que no es de naturaleza puramente civil o privada, sino de carácter mixto (el art. 2497), el que expresamente regula la materia tanto para los órganos del Estado como para los particulares.

$4^{\circ}$. Técnicas utilizadas por la jurisprudencia para aceptar o rechazar la supletoriedad. Se puede sintetizar así: i) no se realiza referencia alguna al art. $4^{\circ} \mathrm{CC}$ para aplicar o no la supletoriedad; ${ }^{28}$ ii) la supletoriedad es considerada legítima cada vez que es aceptada de manera expresa por la normativa especial administrativa (caso del art. $1^{\circ}$ Ley $\mathrm{N}^{\circ} 19.886$ ) o por normas mixtas situadas en el CC (caso del art.2497); iii) la supletoriedad es considerada ilegítima y no es aceptada cada vez que la normativa de derecho público o administrativo ofrece una solución especial en la materia específica, como es el caso de la nulidad de los actos administrativos o de la responsabilidad patrimonial de la administración; iv) las decisiones carecen de matices: o aceptan o rechazan la supletoriedad. Esto es, no se buscan técnicas intermedias, en las cuales se ajuste la norma privada al contexto público, al estilo de la jurisprudencia francesa (en que aplica el principio subyacente en la norma del CC). ${ }^{29} \mathrm{En}$ fin, cabe consignar que la jurisprudencia suele rellenar lagunas con principios jurídicos, sin recurrir a la supletoriedad (tema que no analizo aquí).

\footnotetext{
${ }^{28}$ Disposición que, como reviso infra, es motivo de una discusión doctrinaria; pero no tiene acogida jurisprudencial su aplicación.

${ }^{29}$ Como se resume y analiza en Moderne, Franck, Principios generales del derecho, Thomson Reuters, Santiago, 2004, pp. 145 y 163.
} 


\section{LA DICOTOMÍA PÚBLICO / PRIVADO ANTE LA DOCTRINA NACIONAL: UNA DISCUSIÓN DISCRETA}

Reviso brevemente el panorama de la escasa discusión doctrinaria nacional respecto de la dicotomía; previamente realizo una referencia a la literatura del inicio de la República, dada la ya señalada incorporación de la dicotomía en el Código Civil de 1857.

a) La partitio al inicio de la República. Como adelanto supra III, Andrés Bello incorporó en dos disposiciones del Código Civil la expresión "derecho público"; esto es, una de las partes de la dicotomía. La dicotomía ya era de uso frecuente en la doctrina de la época, ${ }^{30}$ por lo que Bello la manejó a partir esa literatura; seguramente, tomó la expresión de sus lecturas de Savigny, quien fue uno de los autores que más lo influyeron de manera previa a la redacción del Código Civil. ${ }^{31}$ Cabe recordar que Savigny, a propósito de las fuentes del derecho, desarrolla la distinción del derecho en su conjunto, señalando que está dividido en dos ramas: derecho político (que hace sinónimo a derecho público) y derecho privado; división que retoma igualmente al tratar las personas jurídicas, materia esta última en la cual Bello siguió a Savigny muy de cerca. ${ }^{32}$ El otro autor que influyó notablemente en Bello fue Bentham, ${ }^{33}$ pero este último no utilizó en su obra esta dicotomía, siguiendo en ello el modelo inglés. ${ }^{34}$ A partir de esta

\footnotetext{
${ }^{30}$ Véase el pormenorizado y reciente estudio de SoRDI, cit. (n. 4), en especial su capítulo dedicado a los siglos XVII y XIX (pp. 11-95 y 97-137) y las referencias ahí contenidas, en especial de la literatura francesa, que era la manejada especialmente por Bello. Igualmente, véase BIGOT, Grégoire, "La distinction du droit public et du droit privé au prisme de la doctrine française du premier XIX siècle”, en la colectánea: Alvazzi del Fratte, La summa divisio cit. (n. 17 in fine) pp. 15-35.

${ }^{31}$ Cfr.: Guzmán Brito, Alejandro, Andrés Bello codificador. Historia de la fijación y codificación del derecho civil en Chile, Ediciones de la Universidad de Chile, Santiago, 1982, tomo 1, p. 255.

${ }^{32}$ Bello cita a Savigny a partir de la traducción francesa de Ghenoux: Savigny, Frederich Karl, Traité de Droit Romain (Trad. del alemán por M.Ch. Guenoux), Firmin Didot frères, Paris, 1840-1851, 8 vols. Véase lo citado en: $\S 9$ (Derecho privado. Derecho público) y $§ 85$ (Personas jurídicas. Definición). Savigny utiliza primero la expresión "derecho político", seguramente siguiendo a Hegel (Principios de la Filosofía del Derecho, 1821, § 259, a quien cita expresamente); luego utiliza la expresión "derecho público" seguramente siguiendo paralelamente a Kant (Metafisica de las Costumbres. Primera Parte. Principios metafisicos del Derecho, 1797), el que ofrece la división suprema (en su expresión) de derecho público y derecho privado; división que, como es sabido, utiliza Kant para dividir su exposición de la doctrina del derecho en dos partes.

${ }^{33}$ Cfr. Guzmán Brito, Andrés Bello, cit. (n. 30), pp. 258-262.

${ }^{34}$ En notorio que Bentham no utilizaba la dicotomía en su obra; si se revisa sus Traités (Bentham,
} 
incorporación la expresión no dejará de utilizarse en doctrina hasta hoy.

b) Actuales discusiones relativas a la distinción público/privado. En la doctrina nacional no ha habido análisis globales sobre esta materia; las discusiones son recientes y se han reducido a diálogos en dos ambientes doctrinarios.

$\left.1^{\circ}\right)$ Discusiones entre administrativistas y civilistas. Estas discusiones dicen relación: i) con la naturaleza de la partitio, respecto de lo cual han disputado solo dos autores ${ }^{35}$; ii) con el alcance de la norma del art. $4 \mathrm{CC}$, sobre lo cual han existido propuestas de reforma a tal disposición legal y discusiones en torno a ella; ${ }^{36} \mathrm{y}$, iii) con la posibilidad de una supletoriedad general o restringida del CC para resolver casos administrativos, materia que habitualmente enfrenta a algunos civilistas y administrativistas. ${ }^{37}$

Jeremy, Traités de Législations civile et pénale, Bossange père et fils, Paris, 1802, 2a ed., 3 Vol.) en su famoso apartado dedicado a las diversas clasificaciones del saber (Vue génerale d'un corps complet de législation) no aparece referencia alguna a la dicotomía público/privado.

${ }^{35}$ A raíz de las ideas de GuZmán Brito, Alejandro, "Notas sobre el derecho público", Revista de Derecho Público, 1976, No 19-20, pp. 385-393; GuZmán Brito, Alejandro, El derecho privado constitucional, Ediciones Universitarias de Valparaíso, Valparaíso, 2001; Vergara Blanco, Alejandro, "Público y privado ante la dogmática y la teoría del derecho. En especial, las disciplinas de bienes públicos, minas y aguas (a propósito de un reciente libro sobre la «constitucionalización del derecho»)", Revista de Derecho Público, 2004, $\mathrm{N}^{\circ}$ 66, pp. 495-523, discute sus posiciones sobre lo público y privado.

${ }^{36}$ A raíz de Guzmán Brito, Alejandro (dir.); Corral, Hernán; Domínguez, Ramón; Peña, Carlos, "Modificaciones al título preliminar del Código Civil", en: Fundación Fernando Fueyo Laneri (coord.), Estudios sobre reformas al Código Civil y Código de Comercio, Editorial Jurídica de Chile, Santiago, 1999, pp. 40-42, Vergara BlanCo, Alejandro, El Derecho Administrativo como sistema autónomo. El mito del Código Civil como "derecho común”, AbeledoPerrot, Santiago, 2010, discute la interpretación del art. 4 CC. Nuevos análisis en CARRASCO, Edison, "El concepto 'especial' en el Código Civil: diferencias de significación entre el artículo $4^{\circ}$ y el artículo 13”, Revista Ius et praxis, 2014, año 20, No 1, pp. 253-276 y MeJ́As, Claudia, "El derecho común presupuesto en el ordenamiento jurídico nacional. Una revisión de su contenido", Revista chilena de derecho, 2018, Vol. 45, N³, pp. 621-646.

${ }^{37}$ A raíz de las ideas de CORRAL TALCIANI, Hernán, Lecciones de responsabilidad civil extracontractual. Santiago, Editorial Jurídica de Chile, 2003, Vergara Blanco, Alejandro, "Derecho administrativo y supuesta supletoriedad general del Código Civil", Revista de Derecho Administrativo, 2009, № 3, pp. 45-68, y Vergara Blanco, cit. (n. 36), discute sus posiciones. Luego Corral las renueva en Corral Talciani, Hernán, Curso de derecho civil. Parte general, Thomson, Santiago, 2018 y Corral Talciani, Hernán, "El derecho civil como derecho común: ¿mito o realidad? Una respuesta tardía (pero útil) al profesor Alejandro Vergara Blanco", 2020, https://corraltalciani.wordpress.com; las que son contestadas en Vergara Blanco, Alejandro, "Supletoriedad del Código Civil en casos administrativos: respuesta a un crítico mediante un análisis jurisprudencial", El Mercurio Legal, 30 de junio de 2020, https://www. elmercurio.com/Legal. CoRRAL afirma que el Código Civil constituye una especie de derecho común supletorio de "todo el ordenamiento jurídico chileno", para llenar todas sus lagunas jurídicas, no sólo las existentes en normas de derecho privado. La doctrina clásica sólo postulaba el relleno de lagunas al 


\section{$2^{\circ}$ ) Análisis y discusiones entre administrativistas. Al respecto} los textos clásicos de la disciplina del derecho administrativo revisan brevemente la partitio sin teorizar ni marcar contornos precisos. ${ }^{38}$ Pero en los últimos años existen análisis que cabe destacar: i) algunos autores conectan la partitio con la autonomía y coherencia de la disciplina; ${ }^{39}$ ii) otros autores ofrecen análisis más globales de la partitio $;{ }^{40} \mathrm{y}$, iii) en fin hay autores que realizan diversos e interesantes aportes, a veces breves, sobre el tema de la aplicación del CC en determinadas materias administrativas. ${ }^{41}$

En suma, la doctrina nacional no ha profundizado este análisis, a

interior del derecho privado (comercial y civil): véase, en ese sentido el famoso Curso de ALESSANDRI, Arturo; Somarriva, Manuel y Vodanovic, Antonio, Tratado de Derecho Civil. Partes preliminar y general, Editorial Jurídica de Chile, Santiago, T. 1, 2005, pp. 50-52. Sigue la idea tradicional, restringida: ConCHA, Ricardo, Nulidad del contrato de la Administración. Aplicabilidad de las reglas civiles, AbeledoPerrot, Santiago, 2012.

${ }^{38}$ Véase los desarrollos circunspectos de Silva Cimma, Enrique, Derecho administrativo chileno y comparado. Introducción y fuentes, Editorial Jurídica de Chile, Santiago, 1996, $4^{\mathrm{a}}$ ed, pp. 55-57 y 60-68, y Silva Cimma, Enrique, Derecho administrativo chileno y comparado. Introducción y fuentes, Editorial Jurídica de Chile, Santiago, 2009, $5^{\text {a }}$ ed., pp. 59-60 y 62-85; у Sото KLoss, Eduardo, Derecho administrativo. Bases fundamentales, Editorial Jurídica de Chile, Santiago, 1996, T.1, pp. 222-227.

${ }^{39}$ Es el caso de la propuesta de Vergara, El Derecho Administrativo cit. (n. 35), que es discutida por BERMÚDEZ Soto, Jorge, Las relaciones entre el derecho administrativo y el derecho común, AbeledoPerrot, Santiago, 2012.

${ }^{40}$ Son los más desarrollados trabajos de Céspedes Proto, cit. (n. 9), y Céspedes Proto, Rodrigo, "La división del derecho en público y privado en la jurisprudencia judicial y administrativa chilena. Público y privado en derecho administrativo", en Vergara, A.; Bocksang, G. (coords.), Público y privado en derecho administrativo. Actas VIII Jornadas de Derecho Administrativo, Thomson Reuters, Santiago, 2011, pp. 43-93, con ánimo descriptivo incluyendo análisis jurisprudencial; y los trabajos teóricos del autor: Vergara Blanco, Alejandro, "La summa divisio iuris público/privado de las disciplinas jurídicas", Revista de Derecho Universidad Católica del Norte, 2010, Año 17, N 1, pp. 115-128; Vergara Blanco, "Dicotomía público y privado..." cit. (n. 2), pp. 305-326; Vergara Blanco, "La 'summa divisio iuris'..." cit. (n. 2) pp. 43-69; y Vergara BlanCo, Alejandro, Teoría del derecho. Reglas y principios, jurisprudencia y doctrina, Thomson Reuters, Santiago, 2018, pp. 191-211.

${ }^{41}$ Veáse, con análisis interesantes, a veces breves, pero que aportan a la discusión: JARA SchNETtLeR, Jaime, La nulidad de derecho público ante la doctrina y la jurisprudencia, Editorial Libromar, Santiago, 2004, FerradA, Juan Carlos, "El sistema de derecho administrativo chileno: una revisión crítica desde una perspectiva histórica", Revista de Derecho Universidad de Concepción, 2005, N 217-218, pp. 99-118; Ferrada, Juan Carlos, "Los principios estructurales del derecho administrativo chileno: un análisis comparativo", Revista de Derecho Universidad de Concepción, 2007, № 221-222, pp. 99-136; Bermúdez Soto, Jorge, "El principio de legalidad y la nulidad de derecho público en la Constitución Política. Fundamentos para la aplicación de una solución de derecho común", Revista de Derecho Público, 2008, vol. 70, pp.273-285; Bermúdez Soto, Jorge, Derecho administrativo general, Thomson Reuters, Santiago, 2011, p. 23-25, y VALdivia, José Miguel, Manual de derecho administrativo, Tirant lo Blanch, Valencia, 2018, p. 38-41. 
pesar de la existencia de una legislación que consagra la dicotomía y de una jurisprudencia numerosa que produce decisiones que afectan la racionalidad y coherencia de cada polo del derecho.

\section{ESTRUCTURA, IDENTIDAD Y FUNCIÓN DE LA DICOTOMÍA}

Ya he revisado más arriba la dificultad institucional que existe en nuestra tradición jurídica para la recepción de la dicotomía: la ausencia de dualidad jurisdiccional. En el modelo de jurisdicción unitaria, no obstante, son constantes los deslizamientos territoriales, por llamarles así a las aplicaciones cruzadas de las disposiciones de los distintos polos, lo que origina problemas para definir la identidad de cada una de esas partes. Como una primera formulación del problema reviso la estructura de la dicotomía, los efectos que producen los deslizamientos territoriales en la coherencia y autonomía de la disciplina del derecho administrativo y, en fin, las relaciones de colaboración normativa.

\section{1. ¿Qué es lo público? ¿Qué es lo privado?}

a) Cuatro criterios de distinción. En el criterio de Ulpiano el derecho público se refiere al estado de la cosa romana y el derecho privado a la utilidad de cada individuo; esto es, atiende a lo que es útil en uno u otro caso. Modernamente, se suele utilizar dos brocárdicos para caracterizar esas dos nociones enunciando el problema del siguiente modo: "en derecho público solo es posible hacer aquello expresamente permitido" y "en derecho privado es posible hacerlo todo, salvo lo expresamente prohibido". Estos axiomas provienen de las antiguas compilaciones de derecho de origen medieval, los que hoy se traducen, con mayor claridad, en dos célebres principios jurídicos: i) para lo público, impera el principio de juridicidad o legalidad en la actuación de los órganos del Estado y su designio por el interés general; y, ii) para lo privado, el de la autonomía de la voluntad privada y su designio de individuación. Una cuarta descripción de cada uno de los polos es aquella que caracteriza lo público en caso de existencia de potestades de órganos estatales (propias de la autoridad), y lo privado en la autonomía personal. Como se ve, son cuatro perspectivas de lo público y privado; pero hoy en Chile no podemos afirmar cuál de ellas es la que identifica a la dicotomía, en 
especial por la ausencia de criterios generales en su consagración legislativa; asimismo dada la ausencia de una definición jurisprudencial uniforme al respecto y en la falta de una discusión doctrinaria sobre estos aspectos genéricos de la dicotomía.

b) Necesidad de una teoría general. No existe una teorización sobre la identidad y funciones de la división ni de su significado normativo en el Derecho Administrativo. Los análisis existentes son todos temáticos: existe una creciente bibliografía sobre todos los temas más relevantes de esta disciplina y su manifestación regulatoria, pero pareciera pendiente una mirada sistémica, intentando describir lo que unifica a cada uno de esos regímenes separados y su identidad de derecho público.

2. Identidad de lo público, deslizamientos territoriales y colaboración normativa

a) La identidad de lo público. Cabe preguntarse: ¿Cuál es la identidad de lo público en la actual CPR y en la legislación complementaria o especial relativa a la actividad de la Administración? En seguida, cabe siquiera observar si existe una consagración paralela sobre la identidad de lo privado en la CPR y que permita identificar la "legislación común aplicable a los particulares" (como señala el art. $19 \mathrm{~N}^{\circ} 21$ inc. $2^{\circ} \mathrm{CPR}$ ). Preguntas estas que cabe responder previamente a cualquier desarrollo sobre la paridad público/privado, pues esta es una división de dos identidades, en principio, contrapuestas. Salvo petición de principio o error taxonómico, se trata esta división de polos opuestos; por algo es una bipolaridad (ha de existir oposición). Pero esto pudiese ser una mera abstracción o una pretensión ideológica (pretender que sean opuestos), pues en la praxis constitucional, legislativa y jurisprudencial (como se ve más arriba) parecieran tenderse constantes puentes entre ambas esferas, originando permanentes colaboraciones o deslizamientos territoriales: desde y hacia lo público y privado, una y otra vez, sin aquilatar consecuencias más generales o verificar la coherencia material de ello.

b) Coherencia de los traspasos territoriales. Cabe al menos intentar ofrecer definiciones generales que permitan interpretar la coherencia de estos trasvases o deslizamientos territoriales y que no se decidan, en términos jurisprudenciales, únicamente en base a la interpretación estricta de una $\mathrm{u}$ otra disposición legal aislada. Por ejemplo, la aplicación supletoria del CC 
no se debiese decidir únicamente a partir de la interpretación del art.4 de ese código, pues eso origina soluciones binarias y no mixtas (siendo este último el caso de los grandes avances en el derecho comparado en que hay cultura en el manejo jurídico de la partición público / privado $^{42}$ ). Cabe aceptar situaciones intermedias, de colaboración normativa limitada, de respeto por la médula de cada sector de la paridad.

Toda esta realidad en ocasiones produce conflictos de interpretación de normas (las que suelen ser oscuras o lagunosas) en temas cruciales, que en la praxis cruzan lo público y privado, y el apoyo que se suele encontrar en la doctrina y jurisprudencia suele ser mesurado, pues no se ha desarrollado o producido una identificación de lo público en términos más sofisticados y adaptados a los casos especiales; no más que la mera enunciación genérica (aquí también recogida) de su necesaria tendencia o designio del bien común o el interés general. Es necesario recorrer con más precisión, en cada caso o tema relevantes, las fronteras de lo público y privado, determinando sus límites y contornos, de tal manera de hacerlos más conocidos y prefigurados, con una conexión precisa a los términos de la CPR, de la legislación, o de su acogimiento por la jurisprudencia o de su desarrollo doctrinario.

c) Necesidad de identificar lo público en las normas. Lo anterior es la consecuencia de la falta de una exigencia institucional para identificar lo público, a raíz de la unidad jurisdiccional ${ }^{43}$ y de la existencia de una regulación normativa muy escueta en materia administrativa, casi sin leyes generales. Además, las leyes que regulan materias relevantes que definen la esencia de la disciplina no suelen ofrecer desarrollos o definiciones generales: por ejemplo, lo que sea el "servicio público" en sentido funcional o sustantivo; lo que sea el "fomento"; lo que sea la "ordenación" administrativa y su conexión con los intereses generales o el bien común, que pudiese ser la médula de lo público. La doctrina no ha proveído siempre a estas definiciones identitarias, quizás por sus tradicionales disputas.

Todos hablamos y escribimos de lo público (o del "derecho público" o del "sector público"); lo mismo ocurre con lo privado (o del "derecho privado" o del "sector privado"). Entonces, ¿cómo no tener una teoría

\footnotetext{
${ }^{42}$ Es el caso de Suiza y Alemania. Véase, bibliografía cit. en n. 19 y 21.

${ }^{43}$ A diferencia de lo que ocurre en los países que cuentan con un sistema de dualidad jurisdiccional; esto es, que cuentan con tribunales especiales de lo contencioso administrativo, separados de los tribunales civiles o (privados).
} 
general de lo que sea cada par de la distinción? Pues, previo a contraponer dos polos, cabe tener claridad sobre la identidad de cada uno de ellos. Desde la perspectiva del derecho administrativo, siquiera como pensamiento confundente (en oposición al abstractivo propio de una teorización más avanzada) cabe saber lo que no es derecho público para luego poder responder a la cuestión esencial y radical: ¿qué es hoy el derecho público chileno? Primero, desde el punto de vista normativo (pues las leyes especiales citadas se refieren a "normas" de derecho público) y luego conocer su desarrollo jurisprudencial y doctrinario. En principio, pareciera que tanto la doctrina como la jurisprudencia (al igual que el legislador) han dejado el tema de lado, pues no hay desarrollos significativos. Nada comparable a lo que existe en otros países en los tres niveles: normativo, doctrinario y jurisprudencial. Eso es consecuencia de la inexistencia de dualidad jurisprudencial en nuestro país; y pareciera que entre nosotros la expresión se utiliza en base a intuiciones legislativas, jurisprudenciales y doctrinarias, pero no como el fruto de una teorización acogida luego en la praxis. No pareciera que haya una identificación más o menos precisa de lo que sea lo público. Y sin esa primera identificación, desde el derecho administrativo, no será posible ofrecer la segunda identificación exigida por esas normas ejemplares de 1991 y 2003, esto es, calificar la naturaleza de tal o cual ley como de "derecho público" o de "derecho privado"; o, de norma mixta y esto último solo será el resultado de una teorización, categoría ésta no conocida ni reconocida en Chile, pero que ha sido en el derecho comparado (p.ej. en Suiza y Alemania) un hito interpretativo, que posibilita la "colaboración" de ambos sectores normativos.

En esto debiese consistir, pareciera, la identidad y funciones de la paridad público/privado en la disciplina y praxis del derecho administrativo.

\section{La partitio y la integración normativa (supletoriedad)}

La elaboración de disciplinas ha sido un tema constante en el derecho, desde Savigny (como "sistema") a Dworkin (como "prioridad local"). Para Dworkin los jueces, en el intento de lograr que la aplicación de la ley sea «coherente», al aplicar el derecho otorgan una preferencia y relevancia esencial («prioridad local») a las disciplinas especializadas en que se divide el derecho («departamentos» o «provincias») y entre esas divisiones 
identifica lo público y lo privado. ${ }^{44}$ Veamos qué significa eso.

a) El rol del juez. Es decir, el juez, al dictar una sentencia, primero identifica y delimita en qué disciplina o sector del derecho se sitúa el caso, y desde ahí reconoce con mayor precisión las reglas (que, en caso de existir, no puede dejar de aplicar); y, en caso de ausencia de regla (por simplificar así, el «caso difícil»), dirigirá la mirada a los principios jurídicos. El jurista define las disciplinas en su materia, y suele clasificarlas primero en públicas o privadas y, en seguida, a modo de cascada, lo transmite a las normas y principios más específicos, que tendrán una naturaleza jurídica especial, de una rama específica. Así, el resultado es que jueces y juristas suelen situar no sólo disciplinas sino también normas específicas en uno de los dos hemisferios del derecho: derecho público o derecho privado. Esto permite, a lo menos, tres tareas fundamentales: i) la división del derecho en público y privado; ii) la elaboración de disciplinas autónomas; $y$, iii) la racionalización y coherencia de la técnica de la supletoriedad en caso de lagunas normativas en las disciplinas o partes del derecho. Esto último lo analizo enseguida.

b) La supletoriedad. La supletoriedad es un método de integración normativa que opera integrando de un modo subsidiario el texto de las leyes de carácter general o común respecto de aquellas de carácter singular o de excepción (llamadas en la práctica, igualmente, leyes «especiales»). Esta es utilizada en aquellos casos en que la interpretación ofrecida por el jurista o por el juez ha resultado insuficiente para cubrir una laguna legal en el ordenamiento singular; en tal caso es necesario recurrir al ordenamiento legal general o común para extraer de él, la norma que pueda cubrir el vacío.

c) Integración normativa, relleno de lagunas y autonomía de la disciplina. Luego de identificar la naturaleza de las normas (esto es, la disciplina a que cada norma está adscrita), será posible advertir que las normas de cada polo compartirán entre sí bases esenciales y principios jurídicos, lo que podría permitir técnicas de integración normativa, como la supletoriedad; pero eso no sucede en las normas de polos opuestos. De ahí que, ante una ausencia de norma en un cuerpo normativo de derecho público, es más coherente, en principio, recurrir a una norma de otro cuerpo normativo que también fuese de derecho público. La integración normativa es una técnica muy relevante en derecho administrativo pues la normativa

${ }^{44}$ Dworkin, pp. pp. 250-251 [traducc. castellana, pp. 180-181] cit. (n. 15). 
especial administrativa es muy lagunosa y, desde siempre, se ha recurrido a la aplicación de normas del Código Civil en casos de naturaleza administrativa (también se han aplicado normas del Código del Trabajo o del Código Penal). Pero, cabe observar con atención la coherencia de tal trasvase normativo (o "deslizamiento territorial"), pues se trata de disciplinas y normas situadas en polos distintos de la partitio.

d) La utilización del derecho civil en casos de derecho administrativo. La supletoriedad del Código Civil para resolver casos de derecho administrativo implica un reflejo de una realidad histórica y actual: la influencia que el derecho civil ha producido en diversos temas de derecho administrativo (por ejemplo en materia de bienes y contratos), y la utilización, préstamo, transposición, importación, trasplante o injerto, como quiera llamársele, de diversos conceptos y técnicas, ya sea para perfeccionar las técnicas del derecho administrativo o para suplir lagunas regulatorias. Pero un préstamo significa únicamente que el Código Civil ese transforma en una fuente formal y no una fuente material del derecho administrativo. ${ }^{45}$ De otro modo afectaría la autonomía de la disciplina. ${ }^{46}$

\section{Relaciones y colaboración entre las normas contrapuestas de la dicotomía}

Como revisamos, la dicotomía tiene varias aristas; una de ellas es la supletoriedad, que es una relevante técnica normativa de integración de normas para enfrentar las lagunas del ordenamiento escrito; en especial,

\footnotetext{
${ }^{45}$ Como ha puesto en evidencia, para el caso francés, Plessix, L'utilisation du droit civil, cit. (n. 17), p. 820 .

${ }^{46}$ Plessix, L'utilisation du droit civil, cit. (n. 17), p. 819. Es muy expresivo lo que señala este autor, por lo que cabe su cita completa. La autonomía del derecho administrativo respecto del derecho civil, dice, se produjo históricamente en Francia a partir de dos factores: $1^{\circ}$ ) la inaplicabilidad de principio del Código Civil al conjunto de las relaciones relevantes de competencia del juez administrativo; $y, 2^{\circ}$ ) no obstante el carácter lagunoso de la legislación administrativa, el arrêt Blanco de 1873 significó una verdadera declaración de independencia del derecho administrativo respecto del Código Civil. Recuerda PlessIX que en Francia se creó una jurisdicción administrativa separada (el Consejo de Estado) precisamente para que el Código Civil no fuere considerado como un derecho común, esto es, "como un derecho dotado de una autoridad supletoria automática" (p. 819). Agrega que el derecho administrativo es entonces un derecho autónomo en la medida en que el Código Civil no es aplicable de pleno derecho a las relaciones jurídicas de naturaleza administrativa, "donde, en uso de su poder pretoriano, el juez [administrativo] es libre de obtener de las fuentes materiales lo que él juzgue útil técnica o ideológicamente" (p. 820). De ahí que, como anuncio en el texto, la técnica de la supletoriedad puede afectar la autonomía material del derecho administrativo.
} 
la situación más usual, que es la aplicación de normas del CC a casos de derecho administrativo. Se traduce entonces en un problema de relaciones entre ambas esferas del derecho. De ahí que cabe conocer esa relación y las habituales transposiciones.

a) Las relaciones internormativas en un ambiente de dualidad jurisdiccional. Una observación del fenómeno permite revisar esas relaciones normativas, que no se traducen en rivalidades disciplinarias sino en colaboraciones normativas, cuando son adecuadas. Estos deslizamientos territoriales han sido persistentes en la historia jurídica contemporánea. Pero deben ser observados con detalle y perspectiva global a la vez. En el derecho comparado europeo ha habido relevantes avances; en especial se ha constatado que para traspasar una norma de un polo a otro debe adecuarse al sector en que se traspasa. Aun así, en tales órdenes jurídicos se actúa bajo la convicción de que esos traspasos son inevitables, ante la existencia de lagunas normativas. Pero ello se puede afirmar sin preocupación en esos países por la coherencia que se puede lograr en cada uno de los polos en los casos de traspasos territoriales, pues se trata de ambientes institucionales que instauran una dualidad jurisdiccional, con jueces especializados en cada polo del derecho; lo que no es el caso de Chile en que existe predominantemente una unidad jurisdiccional y jueces no especializados.

Pareciera que la perspectiva de la colaboración es la que resulta más apropiada cuando se trata de entender -y disciplinar- fenómenos como la compartición contemporánea de responsabilidades entre la esfera pública/ estatal y el sector privado; entre los órganos del Estado y la sociedad; entre la Administración y el individuo. Ambas esferas, en diversos ámbitos, no son hoy día como dos orillas de un río que nunca se tocan, sino que se produce una creciente interacción, se tienden puentes, el sector privado adquiere responsabilidades públicas que antes correspondían en una mayor medida o casi únicamente a la Administración. Este es el terreno que más atención requiere por parte de la doctrina. El desafío de enfrentar la emergencia producida por el virus Covid-19 en 2020 y 2021 ha sido una nueva y ostensible ocasión en que esa colaboración ha operado en la práctica (entre órganos del "sector público" y entidades del "sector privado") y cabrá observar ex post si estaban preparadas para ello tanto las normas de derecho público como aquellas de derecho privado para dar las respuestas adecuadas. Cabrá realizar una revisión tanto para esta época de excepción como para las épocas de normalidad. 
b) Más allá de la supletoriedad del Código Civil. En fin, cabe abarcar todos los tópicos en que esta discusión es importante, llevándola más allá de la mera aplicación supletoria del Código Civil, en la búsqueda de interconexiones o complementariedades. Sin perjuicio de esto, igualmente cabe observar las discusiones que han existido en la doctrina chilena acerca de tal aplicación supletoria de otros códigos o leyes del sector privado para casos de índole administrativa. Por ejemplo, es el caso de la aplicación supletoria del Código del Trabajo (dictado para regir al "sector privado") a conflictos laborales de funcionarios o empleados de órganos administrativos (esto es, del "sector público"); también es el caso de la aplicación del Código Penal para el ejercicio de la potestad sancionatoria de los órganos de la Administración: son otras manifestaciones de estas alteraciones "territoriales", lo cual ha sido objeto de jurisprudencia reciente y muy abundante, como cito supra.

\section{CONCLUSIONES}

$1^{\circ}$. No existe en nuestro medio una discusión amplia, a pesar de su necesidad, sobre la estructura, identidad y función actual de la partitio entre derecho público y privado, en especial desde la perspectiva de la autonomía formal y material del derecho administrativo. Es necesaria una respuesta sobre la identidad de la disciplina en medio de la partitio público/privado. Esta es una tarea epistemológica de publicistas y privatistas, de parte de sus respectivos especialistas: a cada cual lo suyo, para que desde cada polo del derecho puedan aquilatarse las consecuencias de los deslizamientos territoriales y pronunciarse sobre la coherencia o razonabilidad de los mismos. Solo a través del análisis de la estructura, identidad y función de la divisio en el régimen jurídico chileno, y de una previa observación crítica, es posible obtener respuestas concretas sobre los efectos de la actual normativa y praxis jurisprudencial en la autonomía de la disciplina del derecho administrativo, en la definición de su campo y en las materias capitales de la disciplina. En este trabajo solo realizo una primera observación del status quaestionis en las fuentes y del problema de la dicotomía en la praxis del derecho administrativo.

$2^{\circ}$. La normativa acoge desde el inicio de la República la partitio, en especial el Código Civil; del mismo modo las Constituciones; pero el 
epítome son dos normas de 1991 y 2003 que insertan ambas partes de la división, con consecuencias jurídicas que obligan a la jurisprudencia y doctrina a proponer una definición de cada parte de la división.

$3^{\circ}$. La jurisprudencia ha mostrado un intenso desarrollo de la partitio en diversos temas de derecho administrativo, si bien secundarios, como consecuencia del relleno de lagunas, utilizando la técnica de la supletoriedad para aplicar el Código Civil y otros códigos (del Trabajo y Penal). Todo ello en un sistema judicial unitario, sin jueces especializados, y con resultados diversos en lo que se refiere a la racionalidad del derecho y coherencia de cada polo, en especial el caso del derecho administrativo, que es una disciplina que forma parte del derecho público, para la resolución de cuyos casos se aplica o se intenta aplicar habitualmente normas contenidas en el Código Civil (el que forma parte del derecho privado).

$4^{\circ}$. El diagnóstico de la partitio en la doctrina chilena es matizado. A pesar de que la dicotomía público / privado está presente en las normas desde el inicio de la República, y de su relevancia en el sistema, la doctrina ha disputado relativamente poco sobre el tema. La discusión se ha dado en torno a pocos autores y a escritos más bien breves y el eje de la discusión doctrinaria es la aplicación del Código Civil a casos administrativos, dejando de lado las consecuencias epistemológicas del desarrollo de la partitio en la disciplina.

$5^{\circ}$. Los mayores desafíos de la doctrina del derecho administrativo en cuanto a la dicotomía pareciera que son los siguientes: por una parte, ofrecer una teoría general sobre la materia. Hasta ahora ha habido análisis parciales, pero no se ha identificado la dicotomía como tema relevante de la disciplina. Existen manuales y autores que no la tratan como parte de la misma no obstante su presencia en las fuentes y su conexión con la identidad de la disciplina. Por otra parte, cabe revisar la coherencia de los actuales traspasos territoriales que ha propuesto la legislación y ha aplicado la jurisprudencia, con el mismo objetivo de observar si ello altera la identidad de la disciplina, y en su caso en qué medida lo realiza. 


\section{REFERENCIAS BIBLIOGRÁFICAS}

\section{a) Doctrina}

Alessandri, Arturo; Somarriva, Manuel; Vodanovic, Antonio, Tratado de Derecho Civil. Partes preliminar y general, Editorial Jurídica de Chile, Santiago, 2005, T. I.

Allison, J., A Continental Distinction in the Common Law: A Historical and Comparative Perspective, Oxford University Press, New York, 2000.

Alvazzi del Frate, Paolo; Bloquet, Sylvain; Vergne, Arnaud, La summa divisio droit public/droit privé dans l'histoire des systèmes juridiques es Europe (XIXe.-XXIe. siècles), Institut Universitaire Varenne, París, 2018.

Arce y Flores-Valdés, Joaquín, Derecho civil constitucional, Civitas, Madrid, 1986.

Arendt, Hannah, The Human Condition, Paidós, Barcelona, 1993 (trad. de edición de The University of Chicago Press, 1958).

Auby, Jean-Bernard; Freedland, Mark, La distinction du droit public et $d u$ droit privé: regards francais et britanniques, LGDJ Diffuseur, París, 2004.

Bacellar Filho, Romeu F., Direito Administrativo e o novo Código Civil, Editora Fórum, Belo Horizonte, 2007.

Balbín, Carlos F., Impacto del Código Civil y Comercial en el derecho administrativo, Astrea, Buenos Aires, 2016.

BARnes, Javier, "An Expanding Frontier of Administrative Law: The Public Life of Private Actors (A Functional Approach)", European Public Law, 2018, Vol. 24, N $\mathrm{N}^{\circ}$ 3, pp. 595-612.

BARRAUD, Boris, "Droit public - droit privé: de la summa divisio à la ratio divisio?", Revue de la recherche Juridique - Droit Prospectif, 2014, 1101 ss.

BÉNOIT, Francis-Paul. Le droit administratiffrancais, Dalloz, París, 1968.

Bentham, Jeremy, Traités de Législations civile et pénale., Bossange père et fils, Paris, 1802, 2a ed., 3 Vol.

Bermúdez Soto, Jorge, "El principio de legalidad y la nulidad de derecho público en la Constitución Política. Fundamentos para la aplicación de una solución de derecho común", Revista de Derecho Público, 2008, vol. 70, pp.273-285.

Bermúdez Soto, Jorge, Derecho administrativo general, Thomson Reuters, Santiago, 2011.

BERMúdez Soto, Jorge, Las relaciones entre el derecho administrativo y el derecho común, AbeledoPerrot, Santiago, 2012.

Bigot, Grégoire, "La difficile distinction droit public/droit privé dans 1'ancien droit: 1'exemple du droit administratif', Droits, 2003, No38, pp. 97-111.

Bıoy, Xavier, L'identité du droit public. Presses de l'Université Toulouse I Capitole - LGDJ, Toulouse, 2011.

BobBio, Norberto, Estado, Gobierno y Sociedad, Fondo de Cultura 
Económica, México, 2004.

Bonnet, Baptiste; Deumier, Pascale, De l'intérêt de la summa divisio droit public-droit privé?, Dalloz, París, 2010.

BoullLon, Henri, Recherche sur la définition du droit public, IRJS Éditions, Paris, 2018.

Bullinger, Martin, Derecho público y derecho privado, Olejnik, Santiago, 2018 (trad. de la edición de 1968).

CAmus, Clotilde, La distinction du droit public et du droit privé et le conflit de lois, LGDJ - l'extenso éditions París, 2015.

Carrasco Jiménez, Edison, 'El concepto 'especial' en el Código Civil: diferencias de significación entre el artículo $4^{\circ}$ y el artículo 13", Ius et Praxis, 2014, año 20, $\mathrm{N}^{\circ} 1$, pp. 253-276.

Cassese, Sabino, "Diritto privato/diritto pubblico: tradizione, mito o realtà?", en Conte, G.; Fusaro, A.; Somma, A.; Zeno Zencovich, V. (dirs.), Dialoghi con Guido Alpa, Roma Tre Press, Roma, 2018, pp. 51-56.

Cerulli Irelli, Vincenzo, Amministrazione pubblica e dirritto privato, Giappichelli, Turín, 2000.

Cerulli Irelli, Vincenzo, Lineamenti del diritto amministrativo, Giappichelli, Turín, 2006.

CÉspedes Proto, Rodrigo, "La clasificación del derecho en público y privado en el ordenamiento jurídico chileno", Actualidad Jurídica (Universidad del Desarrollo), 2004, N 9, pp. 273-300.

CÉsPedes Proto, Rodrigo, "La división del derecho en público y privado en la jurisprudencia judicial y administrativa chilena. Público y privado en derecho administrativo", en Vergara, A.; Bocksang, G. (coords.), Público y privado en derecho administrativo. Actas VIII Jornadas de Derecho Administrativo, Thomson Reuters, Santiago, 2011, pp. 43-93.

Chamard, Caroline, La distinction des biens public et des biens privés. Constitution à la définition de la notion de biens publics, Dalloz, Paris, 2004.

Chapus, René, Droit administratif général, Montchestien, Paris, 2000.

Chevrier, Georges, "Remarques sur l'introduction et les vicissitudes de la distinction $\mathrm{du}$ «jus privatum» et du «jus publicum» dans les œuvres des anciens juristes français", Archives de philosophie du droit, 1952, pp. 5-77.

Concha MachucA, Ricardo, Nulidad del contrato de la Administración. Aplicabilidad de las reglas civiles, AbeledoPerrot, Santiago, 2012.

Corral TAlciani, Hernán, Lecciones de responsabilidad civil extracontractual, Editorial Jurídica de Chile, Santiago, 2003.

Corral Talciani, Hernán, Curso de derecho civil. Parte general, Thomson Reuters, Santiago, 2018.

Corral Talciani, Hernán, "El derecho civil como derecho común: ¿mito o realidad? Una respuesta tardía (pero útil) al profesor Alejandro Vergara Blanco", 
2020, https://corraltalciani.wordpress.com consultada:

CoRtés Moncayo, Édgar, "Derecho privado y derecho público. Una summa divisio entre tradición y adaptación”, en: SCHIPANI, S.; CoRTÉs, E. (coords.), Sistema jurídico romanista y subsistema jurídico latinoamericano, Universidad Externado de Colombia, Bogotá, 2013, pp. 37-51.

DAVID, Rene, Los grandes sistemas jurídicos contemporáneos, Aguilar, Madrid, 1968.

De Béchillon, Denys, Qu'est-ce qu'une régle de Droit?, Ed. Odile Jacob, Paris, 1997.

Desdentado Daroca, Eva, La crisis de identidad del Derecho Administrativo: privatización, huida de la regulación pública y Administraciones independientes, Tirant lo Blanch, Madrid, 1999.

Desmons, Éric, "Droit privé, droit public", en Alland, D.; Rials, S. (Coords.), Dictionnaire de la culture juridique, Quadrige-Lamy, PUF, París, 2003, pp. 520525.

Domat, Jean, Les quatre livres du droit public, Caen, Paris, 1989.

Dubey, Jacques; Zufferey, Jean-Baptiste, Droit administratif générale, Helbing Lichtenhahn, Bâle, 2014.

Duguit, León, Manual de Derecho Constitucional, Comares, Granada, 2005 (trad. edición de 1927).

Dupuis, Georges; GuÉDon, Marie-José; ChrétIEn, Patrice, Droit administratif, Sirey, Paris, 2007.

Dworkin, Ronald, Law's Empire, Harvard University Press, Cambridge, 1986.

FerRADA, Juan Carlos, "El sistema de derecho administrativo chileno: una revisión crítica desde una perspectiva histórica", Revista de Derecho Universidad de Concepción, 2005, N²17-218, pp. 99-118.

FerRadA, Juan Carlos, "Los principios estructurales del derecho administrativo chileno: un análisis comparativo", Revista de Derecho Universidad de Concepción, 2007, $\mathrm{N}^{\circ}$ 221-222, pp. 99-136.

García de Enterría, Eduardo; Fernández Rodríguez, Tomás-Ramón, Curso de Derecho Administrativo, Civitas, Madrid, 2012, T. I.

García del Corral, Idelfonso, Cuerpo del Derecho Civil Romano, Ed. Jaime Molinas, Barcelona, 1889.

Garcia Vitta, Heraldo, Aspectos da teoria geral no direito administrativo, Malheiros editores, São Paulo, 2001.

Gaudemet, Yves, Droit amministratif général, LGDJ, Paris, 2001, T.1.

Gaudemet, Yves ; Gaudemet, Sophie, "Droit public, droit privé", Revue de droit Henri Capitant, 2012, N5, http://www.henricapitantlawreview.fr/edito_ revue.php?id $=48 \&$ lateral $=48$.

Gerber, C. F. von, Ueber öffentliche Rechte (Tübingen), Giuffré, Milán, 
1852 (trad. Sui diritto pubblici, Gerber, Diritto pubblico).

Geuss, Raymond, Public Goods, Private Goods. Princeton University Press, 2003.

Gonod, Pascale; Melleray, Fabrice; Yolka, Phillippe, Traité de droit administratif, Dalloz, París, 2011, T. I.

González Navarro, Francisco, Derecho Administrativo Español, Eunsa, Pamplona, 1993.

GrIMm, Dieter, Sobre la identidad del derecho público, Fundación Coloquio Jurídico Europeo, Madrid, 2015.

GuZmán Brito, Alejandro, Andrés Bello codificador. Historia de la fijación y codificación del derecho civil en Chile, Ediciones de la Universidad de Chile, Santiago, 1982, T. 1.

GuZmán Brito, Alejandro, "Notas sobre el derecho público", Revista de Derecho Público, 1976, N 19-20, pp. 385-393.

GuZmán Brito, Alejandro, El derecho privado constitucional, Ediciones Universitarias de Valparaíso, Valparaíso, 2001.

Guzmán Brito, Alejandro (dir.); Corral, Hernán; Domínguez, Ramón; PeÑA, Carlos, "Modificaciones al título preliminar del Código Civil", en: Fundación FERnANDo Fueyo LANERI (coord.), Estudios sobre reformas al Código Civil y Código de Comercio, Editorial Jurídica de Chile, Santiago, 1999, pp. 15-70.

Habermas, Jürgen, Historia y crítica de la opinión pública, G. Gili, Barcelona, 1982 (trad. de la edición de 1962).

Hauriou, Maurice, Précis de droit administratif et de droit public, Dalloz, Paris, 2002 (trad. de $12^{\circ}$ edición de 1933).

HAYEK, Friedrich A., Law, Legislation and Liberty, Routledge, Londres, 1973 Vol. 1, (trad. cast., Madrid, Unión Editorial).

Hegel, G.W. Friedrich, Principios de la Filosofía del derecho, Edhasa, Madrid, 1999 (trad. Juan Luis Vermal de la edición de 1821).

Hesse, Konrad, Derecho Constitucional y derecho privado, Civitas, Madrid, 1995.

Hirschman, Albert, Interés privado y acción pública, Fondo de Cultura Económica, México, 1986 (trad. de Eduardo Suárez, edición de 1982).

Huber, Peter, "Die Demontage des öffentlichen Rechts", en: KLuth, W., Müller, M. (coords.), Wirtschaft - Verwaltung - Recht: Festschrift für Rolf Stober, Heymanns, Köln, 2008.

IRTI, Natalino, La edad de la descodificación, Bosch, Barcelona, 1992.

JARA SchnetTler, Jaime, La nulidad de derecho público ante la doctrina y la jurisprudencia, Libromar, Santiago, 2004.

JELLINEK, Giorgio, System der subjektiven öffentlichen rechte, Mohr Siebeck, Freiburg, 1892 [2020].

JIANG, Jiangyuan, Théorie du droit public, L’Harmattan, París, 2010. 
Kant, Inmanuel, La metafisica de las costumbres, Tecnos, Madrid, 1989 (trad. de Adela Cortina y Jesús Conill a edición de 1797).

Kelsen, Hans, Teoría general del Estado, Comares, Granada, 2002 (trad. de Reed a la edición de 1925).

Lifante Vidal, Isabel, Lo público y lo privado. Problemas de ética jurídica, Editorial BdeF, Buenos Aires, 2018.

Malaret i García, Elisenda, Derecho público y derecho privado en la actuación de la Administración Pública, Marcial Pons, Madrid, 1999.

Malaurie, Philippe ; Morvan, Patrick, Droit Civil. Introduction générale, Defrénois, Paris, 2005.

MarTínez López-MuÑIz, José Luis, "Derecho público y derecho privado, disyuntiva determinante para el Estado de Derecho", Revista de Derecho Administrativo, 2010, $\mathrm{N}^{\circ} 4$, pp. 91-128.

Martín-Retortillo Baquer, Sebastián, El derecho civil en la génesis del derecho administrativo y de sus instituciones, Civitas, Madrid, 1996.

Maurer, Hartmut, Derecho administrativo. Parte general, Marcial Pons, Madrid, 2011.

Mayer, Otto, Derecho Administrativo Alemán, Depalma, Buenos Aires, 1949 (trad. edición de 1903), Parte general, T. I.

Mejías Alonzo, Claudia, "El derecho común presupuesto en el ordenamiento jurídico nacional. Una revisión de su contenido", Revista chilena de derecho, 2018, Vol. 45, N³, pp. 621-646.

Melleray, Fabrice, L'exorbitance du droit administratif en question(s), LGDJ, Paris, 2004.

MerkL, Adolf, Teoría general del derecho Administrativo, Comares, Granada, 2004 (trad. edición de 1927).

Merryman, John Henry, La tradición jurídica romano-canónica, Fondo de Cultura Económica, México, 1971.

Merryman, John Henry y Pérez-Perdomo, Rogelio, The Civil Law Tradition, Stanford University Press, Stanford, California, 2019, 4a ed.

Moderne, Franck, Principios generales del derecho, Thomson Reuters, Santiago, 2017.

Montesquieu, L'Esprit des lois. Reed, Garnier, Paris, Vol. I y II, 2011 [1748].

Moor, Pierre, Droit Administratif. Volume I: Les fondements généraux, Editions Staempfli, Berna, 2012.

Napolitano, Giulio, Pubblico e privato nel diritto amministrativo, Giuffré, Milán, 2003.

Nocera, Guglielmo, Il binomio pubblico-privato nella storia del diritto, Edizioni Scientifiche Italiana, Napoles, 1989.

Oliver, Dawn, Common Values and the Public-Private Divide, Butterworths, London, 1999. 
Oliver, Dawn, 'Pourquoi n'y a-t-il pas vraiment de distinction entre droit public et droit prive en Angleterre?" Revue internationale de droit comparé, 2001, $\mathrm{N}^{\circ}$ 2, pp. 327- 338.

Ommeslaghe, van, P., "Le droit public existe-t-il?" Revue de la Faculté de droit (Université libre de Bruxelles), 2006, Vol. 33, I, pp. 15 y ss.

Papaefthymiou, Sophie, "La distinction «droit privé-droit public» en France entre 1848 et 1900: le paradigme positiviste perdu", Annales de la Faculté de Droit de Strasbourg, Nouvelle Série, 1997, º 1, pp. 101-133.

Passerin d'Entreves, Maurizio y Vogel, Ursula (dir.), Public \& Private. Legal, Political and philosophical perspectives, Routledge, Londres y Nueva York, 2000.

Plessix, Benoît, L'utilisation du droit civil dans l'elaboration du droit administratif, Editions Panthéon-Assas, París, 2003.

Plessix, Benoît, Droit administratif général, LexisNexis, París, 2016.

Pugliatti, Salvatore, "Diritto pubblico e diritto privatto", en: F. CALAsso (ed.), Enciclopedia del diritto, Giuffrè editore, Milán, 1958, XII, pp. 606-746.

Radbruch, Gustav, Filosofía del derecho, Comares, Granada, 1999 [1950]. (trad. José Medina Echevarría).

Rivero Ortega, Ricardo, Administraciones públicas y derecho privado, Marcial Pons, Madrid, 1998.

Roca, María J. (coord.), Derecho público y derecho privado. Diferencias de régimen jurídico y cuestiones actuales de recíproca influencia, Iustel, Madrid, 2015.

Rousseau, Jean-Jacques, Du contrat social, Tecnos, Madrid, 1995 [1762]. (trad. española).

Ruffert, Matthias, The Public-private Law Divide: Potential for Transformation? British Institute of International and Comparative Law, London, 2009.

SACCO, Rodolfo, Antropologia giuridica, il Mulino, Bolonia, 2007.

Savigny, Friedrich Karl, Sistema del derecho romano actual, Editorial Comares, Granada, 2005 (traducción de la edición alemana)

Savigny, Frederich Karl, Traité de Droit Romain (Trad. del alemán por M.Ch. Guenoux), Firmin Didot frères, Paris, 1840-1851, 8 vols.

SchmidT-Assmann, Eberhard, La teoría general del derecho administrativo como sistema, Marcial Pons, Madrid, 2003 [1998].

Schmidt-Assmann, Eberhard, "Reflexiones sobre la distinción entre derecho público y derecho privado", Revista de Derecho Administrativo Económico, 2019, $\mathrm{N}^{\circ} 30$, pp. 233-243.

Silva Cimma, Enrique, Derecho administrativo chileno y comparado. Introducción y fuentes, Editorial Jurídica de Chile, Santiago, 1996, 4a ed.

Silva Cimma, Enrique, Derecho administrativo chileno y comparado. 
Introducción y fuentes, Editorial Jurídica de Chile, Santiago, 2009, $5^{\mathrm{a}}$ ed.

SoRDI, Bernardo, "Verso la grande dicotomia: il percorso italiano", Quaderni fiorentini per la storia del pensiero giuridico moderno, 2016, Vol. XLV, pp. 193209.

Sordi, Bernardo, Public Law before "Public Law”, Oxford University Press, Oxford, 2018.

SoRDI, Bernardo, Oltre la dicotomia tra pubblico e privato: le origini del diritto sociale, Vita e Pensiero, Milano, 2018.

Sordi, Bernardo, Diritto pubblico e diritto Privato. Una genealogía storica, Il Mulino, Bolonia, 2020.

Sото KLoss, Eduardo, Derecho administrativo. Bases fundamentales, Editorial Jurídica de Chile, Santiago, 1996, T.1.

Stern, Klaus, Derecho del Estado de la república Federal Alemana, Centro de Estudios Constitucionales, Madrid, 1987 [1983].

Stolleis, Michael, Histoire du droit public en Allemagne. La théorie du droit public impérial et la science de la police 1660-1800, Presses Universitaires de France, París, 1998.

Troper, Michel, Pour une théorie juridique de l'État, Presses Universitaires de France, París, 1994.

Tusseau, Guillaume, "Le dualisme juridique", en: Bienvenu, J.J.; Petit, J.; Plessix, B.; SeIller, B. (dirs.), La Constitution administrative de la France, Dalloz, Paris, 2012.

Valdivia, José Miguel, Manual de derecho administrativo, Tirant lo Blanch, Valencia, 2018.

VAN MEERBEECK, Jérémie, "Droit public et droit privé: ni summa ni divisio?", La distinction entre droit public et droit privé. Pertinence, influences croisées et questions transversales, Anthemis, Limal, 2019, pp. 9-76.

Velasco Caballero, Francisco, Derecho público más derecho privado, Marcial Pons, Madrid, 2014.

Vergara Blanco, Alejandro, "Público y privado ante la dogmática y la teoría del derecho. En especial, las disciplinas de bienes públicos, minas y aguas (a propósito de un reciente libro sobre la «constitucionalización del derecho»)", Revista de Derecho Público, 2004, N 66, pp. 495-523.

Vergara Blanco, Alejandro, "Derecho administrativo y supuesta supletoriedad general del Código Civil", Revista de Derecho Administrativo, 2009, $\mathrm{N}^{\mathrm{o}} 3$, pp. 45-68.

Vergara Blanco, Alejandro, El Derecho Administrativo como sistema autónomo. El mito del Código Civil como “derecho común”, AbeledoPerrot, Santiago, 2010.

Vergara Blanco, Alejandro, "La summa divisio iuris público / privado de las disciplinas jurídicas", Revista de Derecho Universidad Católica del Norte, 
2010, Año 17, $\mathrm{N}^{\circ}$ 1, pp. 115-128.

Vergara Blanco, Alejandro, "Dicotomía público y privado en derecho administrativo, supletoriedad y clasificación de normas en públicas y privadas", en Vergara, A.; Bocksang, G. (coords.), Público y privado en derecho administrativo. Actas VIII Jornadas de Derecho Administrativo, Thomson Reuters, Santiago, 2011, pp. 305-326.

Vergara Blanco, Alejandro, “La 'summa divisio iuris' público-privado y la integración normativa en materias administrativas", Revista de Derecho Privado, 2014, N²6, pp. 43-69.

Vergara Blanco, Alejandro, Teoría del derecho. Reglas y principios, jurisprudencia y doctrina, Thomson Reuters, Santiago, 2018.

Vergara Blanco, Alejandro, "Supletoriedad del Código Civil en casos administrativos: respuesta a un crítico mediante un análisis jurisprudencial", $E l$ Mercurio Legal, 30 de junio de 2020, https://www.elmercurio.com/Legal.

Viale, Claudio Martín (Dir.), Derecho común y derecho administrativo. Diferencias y contactos, Lerner editores, Buenos Aires, 2009.

Weber, Max, Sociología del derecho, Comares, Granada, 2001 (trad. esp. de la edición de 1922).

Zanobini, Guido, Corso di Diritto Amministrativo, Giuffré, Milán, 1958, T I.

\section{b) Normas citadas}

Constitución Política de la República: artículos 7, $19 \mathrm{~N}^{\circ} 1,19 \mathrm{~N}^{\circ} 9$ inc. $5^{\circ}$, $19 \mathrm{~N}^{\circ} 14,19 \mathrm{~N}^{\circ} 21$ inc. $2^{\circ}, 19 \mathrm{~N}^{\circ} 23 ; 53 \mathrm{~N}^{\circ} 1$ inc. $5^{\circ}, 60$ inc. $4^{\circ}, 65 \mathrm{~N}^{\circ} 4,65 \mathrm{~N}^{\circ} 6$, 109 inc. $1^{\circ} ; 111,115$ inc. $5^{\circ}, 118$ inc. $4^{\circ}, 134$ inc. $4^{\circ} 142$ inc. penúltimo.

Código Civil: artículos 4, 192, 547 inc. $2^{\circ}, 589,592$ inc. $2^{\circ}, 595,598,2497$, $839,847,879,948,1.105,1250,1462,1467,1545,1546,2314,2332,2497,2514$, 2515.

Código del Trabajo: artículos 7 y 485 y ss.

Código Penal: artículos: 94 y 97.

Ley $\mathrm{N}^{\circ}$ 18.575, de 1986, Orgánica Constitucional sobre Bases Generales de Administración del Estado: artículo 42.

Ley $\mathrm{N}^{\circ}$ 18.695, de 1986, Orgánica Constitucional de Municipalidades: artículo 142.

DFL N ${ }^{\circ}$ 850, Ley Orgánica del Ministerio de Obras Públicas y Ley de Caminos: artículo 26

Decreto con Fuerza de Ley $\mathrm{N}^{\circ} 164$, de 1991 [cuyo texto fue fijado por el Decreto Supremo $\mathrm{N}^{\circ}$ 900, de 1996], Ley de Concesiones de Obras Públicas: artículo 21 incs. $1^{\circ}$ y $2^{\circ}$.

Ley $\mathrm{N}^{\mathrm{o}}$ 19.886, de 2003, de Bases sobre Contratos Administrativos de Suministro y Prestación de Servicios: artículo $1^{\circ}$. 
c) Jurisprudencia citada

Extranjera:

Tribunal des Conflits, 8 febrero 1873, Arrêt Blanco [M. Blanco contre Manufacture des tabacs de Bordeaux], 1 suppl. Rec. Lebon 61. [también en www. Legisfrance.gouv.fr]

Nacional (todas de la Corte Suprema)

Corte Suprema, 12 de septiembre de 2012, Acevedo Espinoza, Cristian y otro con Fisco de Chile, Rol 6920-2011.

Corte Suprema, 21 de septiembre de 2015, Albala Chamudes, Fernando con Instituto de Salud Pública de Chile, Rol 3528-2015.

Corte Suprema, 12 de junio de 2019, Alcamino Menichetti, Carolina con Junta Nacional de Jardines Infantiles, Rol 4288-2019.

Corte Suprema, 5 de mayo de 2021, Aldoney Vargas, Gabriel y otro con Huber Von Appen, Ernesto y otro, Rol 4915-2009.

Corte Suprema, 20 de marzo de 2019, Alegría Gómez, Hortensia con Fisco de Chile, Rol 5365-2018.

Corte Suprema, 27 de diciembre de 2017, Astaburuaga Suárez, Patricio con Ministerio de Obras Públicas (2017), Rol 82459-2016.

Corte Suprema, 8 de noviembre de 2019, Báez Vílchez, Rosa con Servicio de Salud Talcahuano, Rol 14909-2019.

Corte Suprema, 17 de abril de 2018, Banco de Chile con Unidad de Análisis Financiero, Rol 38857-2017.

Corte Suprema, 27 de octubre de 2011, Benavides del Villar, René con Fisco de Chile, Rol 900-2009.

Corte Suprema, 28 de marzo de 2007, Biava Alvial, Salvador y otros con Fisco de Chile, Rol 3870-2004.

Corte Suprema, 6 de julio de 2009, Burgos Barriga, Nancy y otros con Fisco de Chile, Rol 3956-2007.

Corte Suprema, 2 de octubre de 2018, Bustamante Martínez, Blanca con Fisco de Chile, Rol 19103-2018.

Corte Suprema, 10 de junio de 2013, Caballero González, Ana María con Servicio Agrícola Ganadero, Rol 4178-2012.

Corte Suprema, 8 de enero de 2018, Casino de Juegos Temuco S.A. con Superintendencia de Casinos de Juego, Rol 2961-2017.

Corte Suprema, 29 de septiembre de 2014, Castro Mena, Gerardo y otros con Fisco de Chile, Rol 7128-2014.

Corte Suprema, 24 de octubre de 2013, Castro Saavedra, Vilma y otros con Fisco de Chile, Rol 1577-2013.

Corte Suprema, 7 de abril de 2016, Castro Salinas, Mónica con Fisco de 
Chile, Rol 22866-2015.

Corte Suprema, 7 de diciembre de 2012, Catanni Ortega, Lidio con Fisco de Chile, Rol 12357-2011.

Corte Suprema, 28 de agosto de 2018, Compañía Minera Zaldivar Limitada con Secretaría Regional Ministerial de Salud, Rol 8420-2017.

Corte Suprema, 4 de septiembre de 2019, Comunidad Habitacional Villa Aconcagua con Servicio de Vivienda y Urbanización, Rol 15489-2018.

Corte Suprema, 12 de septiembre de 2011, Comunidad Martínez Sandoval con Estado de Chile y otro, Rol 5376-2009.

Corte Suprema, 30 de octubre de 2017, Constructora Orión con Servicio de Vivienda y Urbanización de la Región del Bío Bío, Rol 100774-2016.

Corte Suprema, 3 de noviembre de 2014, Contreras Silva, Giselle y otro con Servicio de Salud Atacama, Rol 18456-2014.

Corte Suprema, 27 de marzo de 2013, Coña Colipí, Marta y otros con Fisco de Chile, Rol 11829-2011.

Corte Suprema, 24 de octubre de 2018, Corporación Unión de Trabajadores Ferroviarios de Chile y otro con Secretaría Ministerial de Bienes Nacionales del Biobío y otro, Rol 14911-2018.

Corte Suprema, 27 de mayo de 2015, Cortés Figueroa, Yasna con I. Municipalidad de Concepción, Rol 2881-2015.

Corte Suprema, 4 de abril de 2016, Cortes Torrejon, Mónica con I. Municipalidad de Tocopilla, Rol 17216-2015.

Corte Suprema, 21 de octubre de 2015, De la Torre Rivera, Flodemira con Municipalidad de Buin, Rol 7807-2015.

Corte Suprema, 25 de noviembre de 2013, Dirección General de Aguas de la Región de Antofagasta con Alto Atacama S.A., Rol 7559-2012.

Corte Suprema, 4 de enero de 2013, Droguett Inarejo, Raúl con Ejército de Chile, Rol 5288-2010.

Corte Suprema, 12 de agosto de 2014, Emcoser S.A. con Ojeda Vildoso, Ruperto y otros, Rol 10849-2014.

Corte Suprema, 15 de octubre de 2009, Empresa Eléctrica de AISEN S.A. EDELAYSEN con Dirección Regional de la Superintendencia de Electricidad y Combustibles, Rol 5702- 2009.

Corte Suprema, 10 de septiembre de 2009, Empresa Eléctrica de Antofagasta S.A. con Superintendencia de Electricidad y Combustibles, Rol 3357-2009.

Corte Suprema, 3 de agosto de 2009, Empresa Eléctrica de Aysén S.A. con Superintendencia de Electricidad y Combustibles, Rol 3283-2009.

Corte Suprema, 19 de abril de 2018, Erices Contreras, Karem y otros con Fisco de Chile, Rol 12221-2017.

Corte Suprema, 1 de julio de 2009, Espinosa Loredo, Manuel con Instituto de Normalización Previsional, Rol 5559-2007. 
Corte Suprema, 26 de febrero de 2015, Espinoza Faúndez, Juan con Fisco de Chile, Rol 1144-2015.

Corte Suprema, 24 de agosto de 2016, Farah Silva, María con Superintendencia de Valores y Seguros, Rol 5383-2016.

Corte Suprema, 30 de octubre de 2014, Fernández Farfán, Claudio y otros con Servicio de Salud Arica, Rol 11857-2014.

Corte Suprema, 9 de junio de 2008, Ferro Denis, José Luis con Fisco de Chile, Rol 277-2007.

Corte Suprema, 24 de octubre de 2017, Fisco de Chile con Industrial y Comercial Ferrcentro Limitada, Rol 10377-2017.

Corte Suprema, 9 de enero de 2018, Fisco de Chile con Yáñez Marmolejo, Juan, Rol 11480- 2017.

Corte Suprema, 28 de mayo de 2014, Flores Martinez, Cynthia Rosa con Instituto de Normalización Previsional, Rol 17285-2013.

Corte Suprema, 30 de junio de 2015, Forestal Celco S.A. con Superintendencia de Electricidad y Combustibles, Rol 4503-2015.

Corte Suprema, 31 de agosto de 2010, Fuenzalida Fuenzalida, Zunilda y otros con Fisco de Chile, Rol 4300-2008.

Corte Suprema, 1 de agosto de 2016, Fundación Guillermo Barberis Massa con Prado Muñoz, Juana, Rol 27814-2016.

Corte Suprema, 26 de noviembre de 2014, Gana Valdés, Patricio con Fisco de Chile, Rol 16689-2014.

Corte Suprema, 17 de noviembre de 2014, Gangas Manríquez, Daniel y otros con Fisco de Chile, Rol 23595-2014.

Corte Suprema, 8 de abril de 2013, Gardilcic Harasic, Esteban y otros con Empresa de Servicios Sanitarios de Antofagasta y otro, Rol 8867-2012.

Corte Suprema, 21 de enero de 2013, González Galeno, Nelly con Pacheco Cárdenas, Soto Segura, González Gamaliel y Figueroa Cifuentes, Clenardo, Rol 10665-2011.

Corte Suprema, 12 de agosto de 2014, González Moris, Isidro con Fisco de Chile y otro, Rol 13981-2013.

Corte Suprema, 16 de octubre de 2013, González Plaza, Luis y otros con Fisco de Chile, Rol 14-2013.

Corte Suprema, 13 de agosto de 2015, González Villalobos, Herminia y otros con Fisco de Chile, Rol 5761-2015.

Corte Suprema, 19 de mayo de 2016, Guajardo Soto, Lucía con Servicio de Salud O Higgins, Rol 22878-2015.

Corte Suprema, 3 de enero de 2012, Guardia Escobar, Roberto y otros con CODELCO, Rol 9282-2009.

Corte Suprema, 19 de agosto de 2013, Guitérrez Aburto, José con Fisco de Chile, Rol 681-2013. 
Corte Suprema, 27 de julio de 2017, Gutiérrez Sanzana, Silvia y otra con Fisco de Chile, Rol 68818-2016.

Corte Suprema, 3 de abril de 2017, Hernández Pezo, Marisol y otros con Servicio de Salud Concepción y otro, Rol 18306-2016.

Corte Suprema, 24 de agosto de 2015, Ilabaca Astorga, Rodrigo del Carmen con Municipalidad de Villarrica y otros, Rol 32132-2014.

Corte Suprema, 18 de agosto de 2014, Industria Frigorifica Simunovic S.A. con Comisión de Evaluación Ambiental de la Región de Magallanes y Antártica Chilena, Rol 14432-2013.

Corte Suprema, 3 de julio de 2014, Inmobiliaria Las Delicias S.A. con Fisco de Chile y otro, Rol 8742-2014.

Corte Suprema, 31 de marzo de 2008, Instituto de Normalización Previsional con Coletti Araya, Julio Alejandro, Rol 667-2007.

Corte Suprema, 26 de junio de 2008, Instituto de Normalización Previsional con Gómez Maturana, Carlos, Rol 1672-2007.

Corte Suprema, 10 de marzo de 2010, Instituto de Normalización Previsional con Guianatti Leigthon, Galvarino, Rol 2698-2008.

Corte Suprema, 29 de enero de 2008, Instituto de Normalización Previsional con Olguín Pérez, José Abraham, Rol 5341-2006.

Corte Suprema, 29 de enero de 2009, Instituto de Normalización Previsional con Zamora Méndez, Luis y otros, Rol 3678-2007.

Corte Suprema, 2 de abril de 2012, Instituto de Salud Pública con Laboratorio Bestpharma S.A., Rol 2563-2010.

Corte Suprema, 9 de abril de 2012, Instituto de Salud Pública con Laboratorios Recalcine S.A., Rol 78-2010.

Corte Suprema, 23 de noviembre de 2015, Isapre Cruz Blanca S.A. con Carabineros de Chile y otros, Rol 4374-2015.

Corte Suprema, 11 de diciembre de 2017, Isapre Cruz Blanca S.A. con Superintendente de Salud, Rol 27826-2017.

Corte Suprema, 11 de julio de 2012, Jara Muñoz, Raquel con Fisco de Chile, Rol 8962-2009.

Corte Suprema, 28 de agosto de 2017, Jerez Camus, Claudio con Fisco de Chile, Rol 4961-2017.

Corte Suprema, 17 de diciembre de 2015, Klein González, Myriam y otra con Fisco de Chile, Rol 8659-2015.

Corte Suprema, 20 de enero de 2012, Klein Klein, Edison Leonel con Fisco, Rol 8391-2009.

Corte Suprema, 12 de agosto de 2019, Laboratorios Chile S.A. con Fisco de Chile, Rol 12911-2018.

Corte Suprema, 22 de octubre de 2018, Laboratorios Lafi Limitada con Instituto de Salud Pública A, Rol 8157-2018. 
Corte Suprema, 23 de octubre de 2018, Laboratorios Lafi Limitada con Instituto de Salud Pública B, Rol 44510-2017.

Corte Suprema, 29 de noviembre de 2019, Laboratorios Pharma Investi de Chile S.A. con Instituto de Salud Pública, Rol 16231-2018.

Corte Suprema, 18 de octubre de 2011, Laboratorios Recalcine S.A. con Instituto de Salud Pública, Rol 5565-2009.

Corte Suprema, 17 de junio de 2013, Laboratorios Recalcine S.A. con Instituto de Salud Pública A, Rol 9186-2012.

Corte Suprema, 25 de noviembre de 2013, Laboratorios Recalcine S.A. con Instituto de Salud Pública B, Rol 5493-2013.

Corte Suprema, 25 de noviembre de 2014, Labrador S.A. con Dirección de Vialidad del Ministerio de Obras Públicas y otro, Rol 22830-2014.

Corte Suprema, 13 de octubre de 2015, Las Delicias S.A. con Secretaría Regional Ministerial de Bienes Nacionales de la Región de los Lagos, Rol 89672015.

Corte Suprema, 27 de enero de 2009, Le Roy Barría, Marcela con Esval S.A., Rol 3237-2007.

Corte Suprema, 6 de mayo de 2009, Lillo Nuñez, Marta y otros con Fisco de Chile, Rol 3220-2007.

Corte Suprema, 14 de octubre de 2009, López, Manuel y otro con Fisco de Chile, Rol 5570-2007.

Corte Suprema, 29 de noviembre de 2018, Los Canelos Limitada con Sociedad Agrícola Vásquez Limitada, Rol 35064-2017.

Corte Suprema, 4 de enero de 2018, Mancilla Almonacid, Eduvina con Fisco de Chile, Rol 16687-2017.

Corte Suprema, 27 de marzo de 2013, Martínez Díaz, Margarita y otros con Fisco de Chile, Rol 3913-2011.

Corte Suprema, 2 de abril de 2012, Martins, Alejandro Raúl, Castro Antiguay, Leslie con Instituto de Salud Pública, Rol 2501-2010.

Corte Suprema, 14 de mayo de 2015, Mellado Mardones, Jaime con Fisco de Chile, Rol 715-2015.

Corte Suprema, 27 de marzo de 2013, Millalén Sandoval, Clodovet con Fisco de Chile, Rol 9885-2011.

Corte Suprema, 10 de septiembre de 2015, Minera Ximenita I del Cerro La Joya con Fisco de Chile, Rol 6288-2015.

Corte Suprema, 3 de mayo de 2018, Montexchange S.A. con Unidad de Análisis Financiero, Rol 45141-2017.

Corte Suprema, 30 de septiembre de 2008, Montiel Oyarzún, Marta con Fisco de Chile, Rol 1852-2007.

Corte Suprema, 29 de mayo de 2017, Municipalidad de Nueva Imperial con 
Fuentealba Huircan, Honoré, Rol 68835-2016.

Corte Suprema, 29 de mayo de 2017, Municipalidad de Nueva Imperial con Fuentealba Huircan, Honoré, Rol 68835-2016.

Corte Suprema, 13 de enero de 2016, Muñoz Herrera, Patricio con Fisco de Chile, Rol 3021-2015.

Corte Suprema, 6 de septiembre de 2018, Navarro Reyes, Nelson Ricardo con Fisco de Chile, Rol 13217-2018.

Corte Suprema, 10 de noviembre de 2008, Negrete Peña, Rosa y otros con Fisco de Chile, Rol 2775-2007.

Corte Suprema, 27 de abril de 2011, Nilo Suazo, Margarita con Fisco de Chile, Rol 254-2009.

Corte Suprema, 21 de noviembre de 2013, Novare Agrícola Forestal Limitada con Fisco, Rol 638-2013.

Corte Suprema, 26 de septiembre de 2019, Olate Pérez, Ercira y otros con Servicio de Salud Concepción, Rol 18743-2018.

Corte Suprema, 10 de septiembre de 2019, Opko Chile S.A. con Instituto de Salud Pública, Rol 16230-2018.

Corte Suprema, 4 de diciembre de 2017, Orrego Alvarez, María con Servicio de Vivienda y Urbanización de Coquimbo, Rol 58987-2016.

Corte Suprema, 17 de marzo de 2015, Ortíz Díaz, Lavinia y otro con Fisco de Chile, Rol 1849-2015.

Corte Suprema, 6 de junio de 2012, Ortiz Ortiz, Luzmila y otro con Fisco de Chile, Rol 8732-2009.

Corte Suprema, 4 de junio de 2020, Oscar Jesús Inostroza Bilbao Constructora EIRL con Servicio de Vivienda y Urbanismo Región de Valparaíso, Rol 36478-2019.

Corte Suprema, 11 de septiembre de 2017, Osses Pizarro, Gerardo con Municipalidad de Viña del Mar y otra, Rol 95108-2016.

Corte Suprema, 11 de septiembre de 2017, Osses Pizarro, Gerardo con Municipalidad de Viña del Mar y otra, Rol 95108-2016.

Corte Suprema, 1 de abril de 2015, Ovalle Muñoz, Gabriel con Ministerio de Transportes y Telecomunicaciones, Rol 28440-2014.

Corte Suprema, 4 de enero de 2013, Pablos Torres, María con Fisco de Chile, Rol 6110-2012.

Corte Suprema, 30 de agosto de 2018, Pacific Steam Navigation Company con Fisco de Chile, Rol 18123-2017.

Corte Suprema, 28 de octubre de 2009, Paredes Parra, Patricia con Fisco de Chile, Rol 1597-2008.

Corte Suprema, 15 de abril de 2015, Parraguez Faúndez, Jorge con Fisco de Chile, Rol 1566-2015.

Corte Suprema, 15 de junio de 2012, Pavez Urrutia, Jorge Alberto y otros con Fisco de Chile, Rol 9350-2009. 
Corte Suprema, 28 diciembre 2015, Pavimentos Norte Ltda. con Servicio de Vivienda y Urbanización de Antofagasta, Rol 11566-2015.

Corte Suprema, 27 de agosto de 2009, Peña Solari, Rodolfo con Fisco de Chile, Rol 514-2008.

Corte Suprema, 16 de enero de 2012, Peñablanca con Fisco de Chile y otro, Rol 7188-2009.

Corte Suprema, 3 de diciembre de 2009, Pereira Rojas, Heriberto con Lincoqueo Huenumam, Zoila, Rol 5836-2008

Corte Suprema, 23 de marzo de 2017, Perret Guzmán, Rouget y otros con Corporación Social Municipal de Concepción de Servicio Educacional Salud y Atención de Menores SEMCO, Rol 42433-2016.

Corte Suprema, 29 de julio de 2019, Pesquera B y B Limitada con Fisco de Chile, Rol 29254-2018.

Corte Suprema, 20 de noviembre de 2014, Pettinelli Monje, Manuel Egidio con Fisco de Chile, Rol 23455-2014.

Corte Suprema, 23 de noviembre de 2017Pharmamérica Limitada con Instituto de Salud Pública, Rol 12164-2017.

Corte Suprema, 25 de junio de 2015, Pinto Villablanca, Cecilia y otros con Fisco de Chile, Rol 2850-2015.

Corte Suprema, 17 de julio de 2013, Ponce Montes, Ana y otros con Fisco de Chile, Rol 4798-2011.

Corte Suprema, 22 de noviembre de 2017, Promaq Ingeniería y Construcción Limitada con Secretaría Regional Ministerial de Salud de la Región Metropolitana, Rol 100727-2016.

Corte Suprema, 22 de noviembre de 2017, Promaq Ingeniería y Construcción Limitada con Secretaría Regional Ministerial de Salud de la Región Metropolitana, Rol 100727-2016.

Corte Suprema, 26 de julio de 2011, Quinteros Croff, Silvia con Fisco de Chile, Rol 2623-2009.

Corte Suprema, 4 de abril de 2016, Ramírez Leiva, Hugo y otros con Servicio de Salud Metropolitano Norte, Rol 3952-2015.

Corte Suprema, 19 de enero de 2015, Retamales Araneda, Aida del Carmen con Fisco de Chile, Rol 26521-2014.

Corte Suprema, 27 de agosto de 2009, Retamales Olivares, Valeria y otros con Fisco de Chile, Rol 5600-2007.

Corte Suprema, 10 de octubre de 2012, Richard Torres, Eliseo y otros con Fisco de Chile, Rol 4527-2010.

Corte Suprema, 4 de septiembre de 2017, Rodríguez Nieto, Romina con Fisco de Chile, Rol 397-2017.

Corte Suprema, 4 de septiembre de 2017, Rodríguez Nieto, Romina con Fisco de Chile, Rol 397-2017. 
Corte Suprema, 7 de mayo de 2018, Roig Soto, Carmen Patricia con Fiscal de Chile, Rol 765- 2018.

Corte Suprema, 14 de diciembre de 2010, Rojas Castañeda, Ana con Fisco de Chile, Rol 6458-2008.

Corte Suprema, 23 de abril de 2015, Rojas Robledo, Eduardo con Fisco de Chile, Rol 23434-2014.

Corte Suprema, 13 de julio de 2009, Rojas Torres, Diego y otra con Fisco de Chile, Rol 6986-2007.

Corte Suprema, 13 de abril de 2012, Rosales Nacarate, Laurisa con Fisco de Chile, Rol 6582-2009.

Corte Suprema, $1^{\circ}$ de septiembre de 2010, Rosas Vergara, Victor con Fisco de Chile, Rol 1741-2008.

Corte Suprema, 25 de marzo de 2008, Ruz Castillo, Pedro y otro con Fisco de Chile, Rol 743-2007.

Corte Suprema, 30 de noviembre de 2015, Salas Arriagada, Sergio con Municipalidad de Pica, Rol 10666-2015.

Corte Suprema, 19 de noviembre de 2014, Salgado Salgado, Juan Antonio con Fisco de Chile, Rol 7888-2014.

Corte Suprema, 28 de diciembre de 2010, Sánchez Rivas, Olga y otros con Fisco de Chile, Rol 7105-2008.

Corte Suprema, 4 de mayo de 2012, Segura Soto, Pabla con Fisco de Chile, Rol 9718-2009.

Corte Suprema, 28 de julio de 2014, Senerman Rapaport, Abraham con Fisco de Chile, Rol 10782-2014.

Corte Suprema, 30 de diciembre de 2015, Sociedad Agrícola y Ganadera El Tangue Limitada con Fisco de Chile, Rol 14034-2015.

Corte Suprema, 5 de octubre de 2006, Sociedad de Deportes Palestina S.A. con Municipalidad de Las Condes, Rol 1696-2005.

Corte Suprema, 23 de octubre de 2014, Sociedad Weltgrund Limitada con Dirección de Vialidad, Rol 8109-2014.

Corte Suprema, 28 de septiembre de 2012, Sotomayor Corvalán, María y otro con Fisco de Chile, Rol 12055-2011.

Corte Suprema, 7 de mayo de 2018, Sweet Délano, Peter con Fisco de Chile, Rol 3663-2017.

Corte Suprema, 14 de abril de 2011, Tamayo Romero, Graciela con Fisco de Chile, Rol 123-2009.

Corte Suprema, 10 de marzo de 2010, Tenorio Aguilera, Verónica y otro con Fisco de Chile, Rol 2493-2008.

Corte Suprema, 31 de mayo de 2010, Toro Vélez, Esmeralda con Fisco de Chile, Rol 3791-2008.

Corte Suprema, 27 de julio de 2017, Vargas Antonio, Claudio con Fisco de 
Chile, Rol 70561-2016.

Corte Suprema, 13 de mayo de 2008, Vera Hermosilla, María y otros con Pinochet Ugarte, Augusto y otros, Rol 3872-2008.

Corte Suprema, 23 de junio de 2011, Vera Santander, Lidia y otros con Fisco de Chile, Rol 558-2009.

Corte Suprema, 8 de mayo de 2012, Vila Avila, Iván Rafael y otros con Menadovich del Río, Miguel y otros, Rol 5735-2009.

Corte Suprema, 23 de junio de 2016, Vio Graepp, Victor con Fisco de Chile, Rol 18297-2016.

Corte Suprema, 7 de diciembre de 2015, Viscay Chávez, Ruby con Fisco de Chile, Rol 3140-2015.

Corte Suprema, 11 de mayo de 2010, Weinstein Maneiu, Alejandro con Instituto de Salud Pública, Rol 4627-2008.

Corte Suprema, 30 de agosto de 2011, Weinstein Manieu, Alejandro Esteban con Instituto de Salud Pública, Rol 7629-2009.

Corte Suprema, 30 de noviembre de 2011, Zúñiga González, Francis y otro con Fisco de Chile, Rol 6299-2009. 